Letícia Ogushi Romeiro Ramires

\title{
Análise da fonte e composição da poluição atmosférica em diferentes locais da região metropolitana de São Paulo.
}

Dissertação apresentada a Faculdade de Medicina da Universidade de são Paulo para a obtenção do título de

Mestre em ciências

Programa de Fisiopatologia Experimental

Orientador: Prof. Dr. Paulo Hilário Nascimento Saldiva. 
Letícia Ogushi Romeiro Ramires

\section{Análise da fonte e composição da poluição atmosférica em diferentes locais da região metropolitana de São Paulo.}

Dissertação apresentada a Faculdade de Medicina da Universidade de São Paulo para a obtenção do título de

Mestre em ciências

Programa de Fisiopatologia Experimental

Orientador: Prof. Dr. Paulo Hilário Nascimento Saldiva.

(Versão corrigida CoPGr 6018/11, de 1 de novembro de 2011. A versão original está disponível na Biblioteca da FMUSP) 


\section{Dados Internacionais de Catalogação na Publicação (CIP) Preparada pela Biblioteca da \\ Faculdade de Medicina da Universidade de São Paulo}

\section{Creprodução autorizada pelo autor}

\section{Ramires, Letícia Ogushi Romeiro}

Análise da fonte e composição da poluição atmosférica em diferentes locais da região metropolitana de São Paulo / Letícia Ogushi Romeiro Ramires. -- São Paulo, 2012.

Dissertação(mestrado)--Faculdade de Medicina da Universidade de São Paulo.

Programa de Fisiopatologia Experimental.

Orientador: Paulo Hilário Nascimento Saldiva.

Descritores: 1.Poluição do ar 2.Poluentes do ar 3.Material particulado

USP/FM/DBD-364/12 


\section{Agradecimentos}

Ao Professor Dr. Paulo Hilário Nascimento Saldiva pela orientação, ajuda, inspiração, paciência em ensinar e apoio em todos os momentos em que precisei.

À Professora Dra. Maria de Fátima Andrade, pelas sugestões e disposição em ajudar, por disponibilizar o IAG para a coleta de dados, e o Lapat - Laboratório de Análise dos Processos Atmosféricos para a análise das amostras.

Ao Dr. Marco Antonio Garcia Martins pelo apoio, sugestões e conselhos desde o inicio do mestrado, e pela imensa ajuda na interpretação dos dados e escrita da dissertação.

Ao Dr. Paulo Afonso André por fornecer o equipamento utilizado no projeto.

Aos Pesquisadores do Lim 05 - Laboratório de Investigação Médica, Eliane Tigre, Luis Afonso, Marcia Hage, Rosa e Paula, pelos bons conselhos e por estarem sempre dispostos a ajudar.

À Pesquisadora Dra. Ana Júlia Lichtenfels pela ajuda na coleta de pelos bons conselhos e estar sempre disposta a ajudar.

Aos técnicos do Lapat pela ajuda com as análises laboratoriais. 
Aos meus pais, Aloísio e Neuza, minha irmã Heloisa e minha tia Quicuco pelo apoio incondicional durante todo o curso, e ajuda nos momentos mais difíceis.

Ao meu noivo Ricardo pela paciência, compreensão e ajuda em todos os momentos que precisei.

Às secretarias Maria de Fátima Stanguet, Rosana Gonçalves, Liduvina Barros e Tânia Souza que estiveram sempre dispostas a ajudar.

À FAPESP pelo apoio financeiro que permitiu a execução do trabalho.

À CETESB por disponibilizar espaço dentro da sua estação de monitoramento para a instalação dos equipamentos de amostragem. 


\section{Resumo}

Ramires L.O.R. Análise da fonte e composição da poluição atmosférica em diferentes locais da região metropolitana de São Paulo [Dissertação]. São Paulo: Faculdade de Medicina, Universidade de são Paulo; 2012.

Grandes cidades, como São Paulo, são afetadas de forma significante pela poluição atmosférica. É de grande importância a caracterização das fontes emissoras da poluição atmosférica, não somente nas regiões centrais, mas também nas regiões periféricas, pois a composição da poluição pode não ser homogênea em toda a extensão da cidade. Neste estudo foram caracterizados os componentes da poluição atmosférica em quatro regiões dentro cidade de São Paulo. Para este fim foram Coletados Material Particulado $\left(\mathrm{PM}_{2.5}\right)$ durante vinte dias no período de inverno de 2011 e vinte dias durante o período de verão de 2011. O material foi coletado através de filtros de policarbonato com $24 \mathrm{~h}$ de exposição, e foi submetido a análises gravimétricas, determinação da concentração de Black Carbon por refletância e determinação da composição elementar por Fluorescência de Raios-X. A identificação das diferentes fontes geradoras de material particulado foi baseada na análise de Componentes Principais (ACP). A variação da concentração da massa do material particulado fino $\left(\mathrm{PM}_{2.5}\right)$ em $\mu \mathrm{g} / \mathrm{m}^{3}$ não teve diferença significativa entre os locais amostrados, mas mostrou diferença entre as estações do ano, sendo maior no período do inverno em todos os locais. A proporção do Black Carbon teve um comportamento diferente da massa. O Black Carbon não variou significantemente entre as estações do ano, porém apresentou diferença entre os locais amostrados, destacando-se no Parque do Ibirapuera e na Zona Leste. Foram encontrados 3 Fatores que explicam $75 \%$ da variabilidade. O Fator 1 é constituído pelos elementos $\mathrm{Ti}, \mathrm{V}, \mathrm{Mn}, \mathrm{Fe}, \mathrm{Ni}, \mathrm{Pb}, \mathrm{P}, \mathrm{S} \mathrm{Cr}$ e $\mathrm{K}$ e foi atribuído como sendo associado à ressuspensão de solo e emissões veiculares, O Fator 2 é composto por $\mathrm{V}, \mathrm{P}, \mathrm{BC}$, e S e foi interpretado como sendo representativo de emissões veiculares de combustíveis com alto teor de enxofre. O Fator 3 é 
associado aos elementos $\mathrm{BC}$ e $\mathrm{Ni}$ e foi interpretado como sendo produzido por emissões veiculares em geral.

Descritores: Material Particulado; Poluentes do ar; Poluição do ar. 


\section{Abstract}

Ramires L.O.R. Analysis of source and composition of air pollution in different locations in the Metropolitan Region of São Paulo [Dissertação]. São Paulo: Faculdade de Medicina, Universidade de São Paulo; 2012.

Large cities such as São Paulo are significantly affected by air pollution. It is of great importance to characterize the emission sources of air pollution, not only in the central regions of the city of São Paulo, but also in peripheral regions, do to the fact that the composition of pollution may not be homogeneous across the city area. This study shows the Characterized the components of air pollution in four different areas of the metropolitan region of São Paulo. Particulate matter ( $\left.P M_{2.5}\right)$ was collected during the winter of 2011 and summer of 2011. It was collected 24-h $\mathrm{PM}_{2.5}$ samples, employing gravimetry to determine $\mathrm{PM}_{2.5}$ mass concentrations; reflectance to quantify black carbon concentrations and $\mathrm{X}$-ray fluorescence to characterize elemental composition. $\mathrm{A}$ receiver model based on principal component analysis (PCA) was used to identify the involvement of the different sources for the generation of particulate matter. The fine particulate matter $\left(\mathrm{PM}_{2.5}\right)$ in $\mu \mathrm{g} / \mathrm{m}^{3}$ did not differ significantly among the locations. However, the results collected showed differences according the seasons evaluation, being higher in the winter for all regions sampled. The proportion of Black Carbon behaves differently than the mass. It does not vary significantly between the seasons, but between the different regions. The proportion of Black Carbon was higher in lbirapuera Park and the East Zone. Was found 3 factors explaining $75 \%$ of the variability. Factor 1 consists of the elements $\mathrm{Ti}, \mathrm{V}, \mathrm{Mn}, \mathrm{Fe}, \mathrm{Ni}, \mathrm{Pb}, \mathrm{P}, \mathrm{S} \mathrm{Cr}$ e $\mathrm{K}$ and was related to crustal emission (soil) and vehicle emissions, Factors 2 consists of the elements $V, P, B C$, e $S$ and can be related to vehicular emissions of fuels with high sulfur content. Factor 3 consists of the elements $\mathrm{BC}$ and $\mathrm{Ni}$ was associated to vehicle emission.

Descriptors: Particulate matter; air pollutants; air pollution 


\section{Sumário}

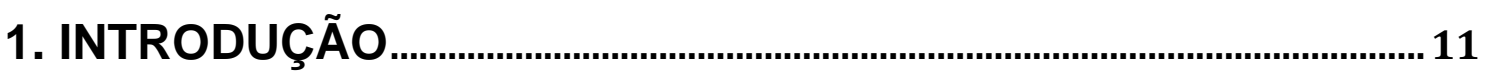

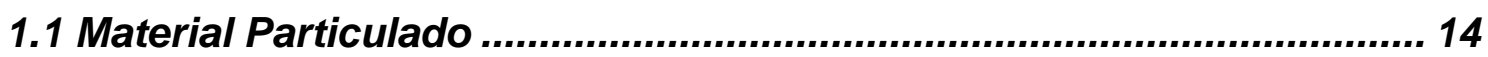

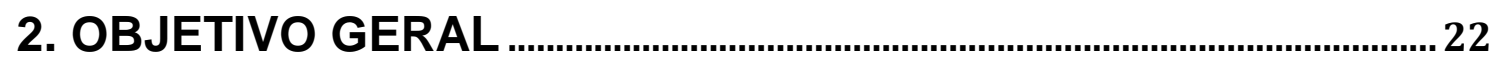

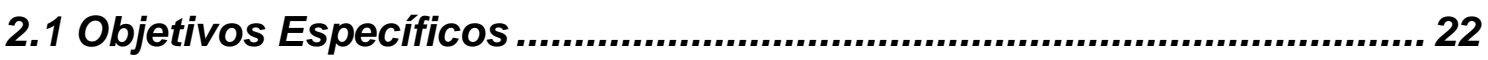

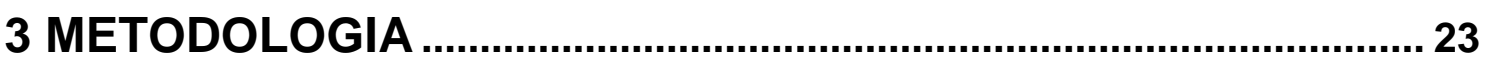

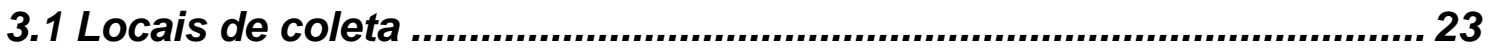

3.1.1 Faculdade de Medicina da Universidade de São Paulo ....................... 23

3.1.2 Cidade Universitária ..................................................................... 24

3.1.3 Zona Leste (próximo Avenida Aricanduva, 5500).............................. 24

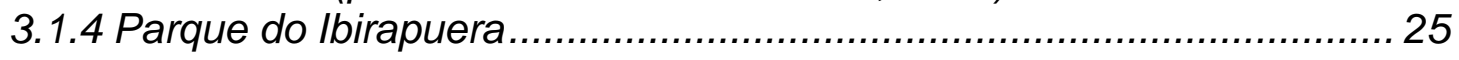

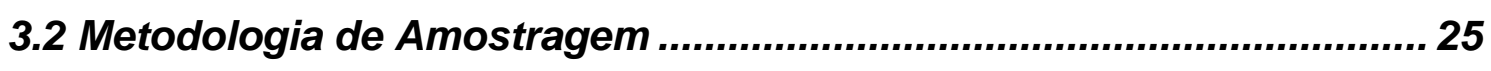

3.2.1 Amostrador de Particulado Fino ........................................................ 26

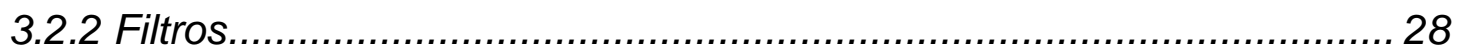

3.2.3 Balança e Descarregador Eletrostático ............................................. 29

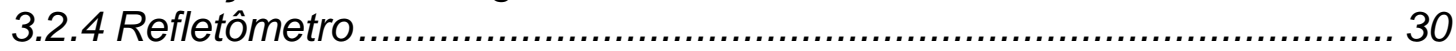

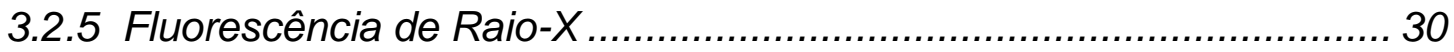

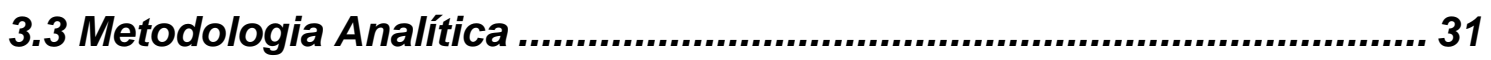

3.3.1Medidas Gravimétricas .............................................................. 31

3.3.2 A determinação da concentração de Black Carbon por refletância....... 31

3.3.3 Determinação da composição elementar por Fluorescência de Raio-X32

3.4 Estatísticas 34

4 RESULTADOS E DISCUSSÃO …................................................ 35

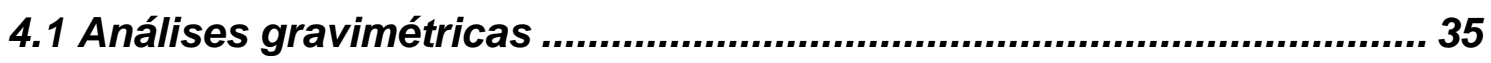

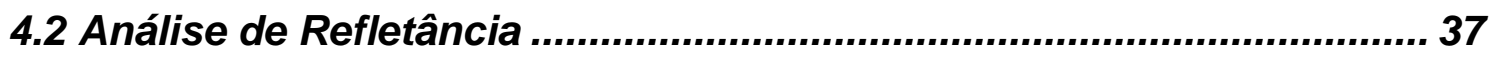

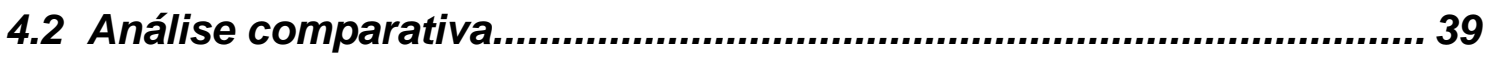


4.3 Análise elementar.

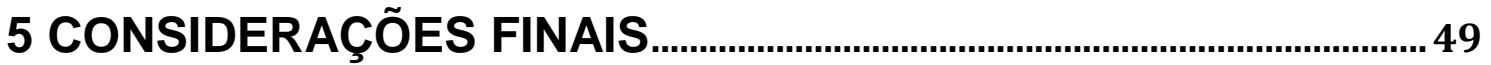

6 BIBLIOGRAFIA 


\section{Introdução}

A atmosfera é um sistema constituído por gases, partículas líquidas e sólidas, que interagem química e fisicamente. É composta principalmente de Nitrogênio( $\left.\mathrm{N}_{2}\right)(78 \%)$, Oxigênio $\left(\mathrm{O}_{2}\right)(21 \%)$ e Argônio(Ar)(1\%). O vapor de água é encontrado principalmente na baixa atmosfera e sua concentração é muito variável, chegando a $3 \%$, evaporação e precipitação controlam a sua abundância. Os constituintes restantes gasosos, os gases residuais, representam menos de $1 \%$ da atmosfera. Estes gases desempenham um papel crucial no equilíbrio radioativo da Terra e nas propriedades químicas da atmosfera. As abundâncias desses gases-traço mudaram rapidamente e notavelmente nos últimos dois séculos (Seinfeld e Pandis, 1998).

A atmosfera de um centro urbano é um complexo sistema constituído por gases e partículas que podem se tornar poluentes quando excedem as concentrações naturais da atmosfera. Podem ser emitidas por fontes naturais, tais como solo, Pólen e vulcões, ou atividades humanas, tais como queima de combustíveis, atividades agrícolas e industriais, etc. (Seinfeld e Pandis, 1998).

O nível de poluição atmosférica no Brasil é determinado pela quantificação das substâncias poluentes presentes no ar, conforme a Resolução CONAMA № 3 de 28/06/1990. Considera-se poluente atmosférico "qualquer forma de matéria ou energia com intensidade e em quantidade, concentração, tempo ou características em desacordo com os níveis estabelecidos, e que tornem ou possam tornar o ar impróprio, nocivo ou 
ofensivo à saúde, inconveniente ao bem-estar público, danoso aos materiais, à fauna e à flora ou prejudicial à segurança, ao uso e gozo da propriedade e às atividades normais da comunidade"(CETESB, 2011).

São duas as principais fontes de emissão associadas à contaminação do ar urbano: as indústrias, desde o início da revolução industrial até os dias atuais, e os veículos automotores, que vêm se transformando na principal fonte de emissão a partir da segunda metade do século XX (Saldiva, et al., 2002).

A Região Metropolitana de São Paulo (RMSP) é constituída por 39 municípios, 38 dos quais se agrupam em torno da capital do Estado e são diretamente ou indiretamente polarizados por ela. Representa 3,4\% do total do território do Estado, concentrando aproximadamente 20 milhões de habitantes (Secretaria dos Transportes Metropolitanos do Governo do Estado de São Paulo).

Os automóveis contribuem em grande escala para a poluição atmosférica, a RMSP possui duas mil grandes indústrias e uma frota de mais de sete milhões de veículos, dos quais $6,5 \%$ são veículos pesados, movido a diesel, e 93,5\% são veículos leves. Destes 76,3\% queimam uma mistura de $78 \%-80 \%$ (v/v) de gasolina com $22 \%$ de etanol e $17,2 \%$ usam etanol hidratado(95\% etanol + água), segundo dados da CETESB (2009). O crescimento acelerado da frota veicular fez com que este se tornasse a principal fonte de emissão de poluentes do ar na RMSP, ultrapassando a contribuição das fontes fixas (CETESB, 2009).

Devido aos problemas de qualidade do ar que ocorrerem principalmente em função dos poluentes provenientes dos veículos na RMSP, o Programa de Controle da Poluição do Ar por Veículos Automotores (PROCONVE), principal 
programa de controle das emissões veiculares tem sido responsável por significativa redução do impacto ambiental, principalmente de monóxido de carbono e de material particulado na RMSP (CETESB, 2011). A cidade de São Paulo (SP) foi escolhida para ser alvo deste estudo porque destaca-se como centro financeiro, industrial e comercial de abrangência regional, nacional e global. Além disso, sua população diariamente exposta e diretamente afetada pela poluição atmosférica.

De acordo com a classificação de Koppen, o clima de São Paulo é Cwa, também chamado de subtropical úmido, caracterizado por um inverno seco e um verão bastante chuvoso (Estação Meteorológica do IAG/USP). proporcionando com isso condições mais desfavoráveis à dispersão de poluentes na atmosfera durante o inverno(CETESB, 2009).

A poluição do ar na cidade de São Paulo, assim como na maioria dos grandes centros urbanos, é uma mistura complexa de compostos de toxidade variável e em sua maioria são originados pelo tráfego de veículos automotores.

Esta mistura de compostos varia de acordo com a proximidade da fonte poluidora, tipo de combustível utilizado e presença de outras fontes de emissão (WHO, 2005).

Dentro das grandes cidades, a intensificação do uso e ocupação do solo é forçada a ocorrer de maneira vertical, pois os terrenos apropriados para construções já se encontram quase completamente edificados (NUCCI, 1999).

Essa verticalização das construções faz com que a superfície de concreto, com alta capacidade térmica, aumente. Todo este procedimento leva a uma diminuição da evaporação, a um aumento da rugosidade e da capacidade térmica da área. Segundo Lombardo (1985), estas três 
modificações são os principais parâmetros que determinam as ilhas de calor encontrada nas grandes metrópoles. Além disso, a acentuada verticalização impede a difusão dos ventos da camada inferior da troposfera, aumentando as ilhas de calor, que dificultam a remoção de poluentes e geram uma situação de risco para todos os que neles transitam ou habitam (Lombardo, 1985)

O cotidiano da população de cidades como São Paulo leva seus habitantes a uma exposição contínua a altos índices de poluição do ar, principalmente durante os meses de outono e inverno (Jacobl, 1999). Os habitantes destas grandes cidades podem ser comparados à bioindicadores, pois a concentração de poluentes leva uma grande parte da população a apresentar problemas de saúde (Brunekreef, 2002).

\subsection{Material Particulado}

O aerossol atmosférico (ou material particulado) é definido como partículas sólidas e líquidas em suspensão na atmosfera. Sua composição e tamanho dependem das fontes de emissão e de processos físico-químicos que ocorrem na atmosfera. Emitidos diretamente como partículas (aerossol primário) ou formado na atmosfera pela conversão gás-partícula (aerossol secundário), os aerossóis atmosféricos variam seus diâmetros na faixa de alguns nanômetros $(\mathrm{nm})$ a dezenas de micrômetros $(\mu \mathrm{m})$. (Brasseur, 1999; Seinfeld e Pandis, 1998). 
Segundo Baird (2002), o Material Particulado pode ser classificado em quatro categorias. As Partículas Totais em Suspensão (PTS) são caracterizadas por apresentarem diâmetro aerodinâmico igual ou inferior a $100 \mu \mathrm{m}$. As Partículas Inaláveis apresentam diâmetro aerodinâmico menor ou igual a $10 \mu \mathrm{m}$ e são classificadas em, Partículas grossas $\left(\mathrm{PM}_{10-2.5}=\right.$ partículas entre $2,5 \mu \mathrm{m}$ e $10 \mu \mathrm{m})$, partículas finas $\left(\mathrm{PM}_{2.5} \leq 2,5 \mu \mathrm{m}\right)$ e Particulas ultrafinas $\left(\mathrm{PM}_{0.1} \leq 0,1 \mu \mathrm{m}\right)$. A principal característica das partículas inaláveis é transportar gases adsorvidos em sua superfície até as porções mais distais das vias aéreas (alvéolos), onde ocorrem as trocas gasosas no pulmão (Braga et al., 2001).

A categoria de partículas grossas é geralmente constituída por partículas primárias, formadas a partir de processos mecânicos, como ressuspensão de poeira do solo, cinzas de combustão, sal marinho e emissões biogênicas naturais (Seinfeld e Pandis, 1998).

A categoria de partículas finas contém partículas primárias geradas por processo de combustão em indústrias, veículos e partículas secundárias geradas na atmosfera pela conversão gás-partícula (Seinfeld e Pandis, 1998).

O Material Particulado tem um tempo de permanência de dias a semanas na atmosfera dependendo do seu diâmetro e peso. Pode ser disperso pelo vento a longas distancias, interferindo na química e física da atmosfera em escala global (Seinfeld e Pandis, 1998).

Os aerossóis podem ser removidos da atmosfera por deposição seca ou úmida. A deposição seca consiste na ação da gravidade sobre as partículas, sendo mais eficiente na remoção de partículas grossas. Na deposição úmida a remoção de partículas ocorre dentro e abaixo das nuvens, devido à 
precipitação. Pelo motivo de as deposições seca e úmida possuírem tempo de residência relativamente curtos na troposfera, e devido à distribuição geográfica das partículas não ser uniforme, os aerossóis troposféricos variam muito em suas concentrações e composições (Seinfeld e Pandis, 1998).

Considerando que os gases atmosféricos têm vida útil variando de menos de um segundo a um século ou mais, tempos de residência de partículas na troposfera variam apenas de alguns dias a algumas semanas (Seinfeld e Pandis, 1998).

Os aerossóis podem se originar de diversas fontes, tais como atividades antropogênicas, conversão gás-partícula, erosão eólica, oceanos e ressuspensão do solo. Uma vez que a maioria dos aerossóis urbanos finos é de origem secundária devido às atividades antropogênicas, a conversão gáspartícula desempenha um papel importante, em especial nos processos em que os gases reagem quimicamente sobre a superfície de partículas préexistentes, formando produtos líquidos ou sólidos, esse processo não resulta na formação de novas partículas, apenas resulta na adição de massa e novas espécies químicas nas partículas já existentes. O processo que dá origem a novas partículas é o de nucleação homogênea e heterogênea que pode ainda ser homomolecular ou heteromolecular, assim há uma considerável variação na composição e propriedades físicas das partículas, dependendo da fonte e também das condições meteorológicas, além da localização geográfica (Miranda et al., 2001; Hobbs, 2000; Jacobson, 2005).

Os aerossóis também desempenham um importante papel no clima e no ciclo hidrológico. No contexto de mudanças climáticas, o estudo do aerossol se concentra na descrição global de suas fontes e na sua distribuição espacial, 
mostrando assim que seu efeito direto sobre o balanço de energia na Terra está ligado ao espalhamento e absorção da radiação solar. Os estudos voltados para microfísica de sua formação e evolução indicam ainda um importante efeito indireto: servem como núcleos de condensação para a formação de nuvens (Raes et al, 2000; Seinfeld e Pandis, 1998; Hobbs, 2000).

\subsection{Padrões de qualidade do ar e saúde}

Os Padrões de Qualidade do $\operatorname{Ar}$ (PQAr), segundo publicação da Organização Mundial da Saúde (OMS) em 2005, variam de acordo com a abordagem adotada para balancear riscos à saúde, viabilidade técnica, considerações econômicas e vários outros fatores políticos e sociais, que por sua vez dependem, entre outras coisas, do nível de desenvolvimento e da capacidade nacional de gerenciar a qualidade do ar.

As diretrizes recomendadas pela OMS levam em conta esta heterogeneidade e, em particular, reconhecem que, ao formularem políticas de qualidade do ar, os governos devem considerar cuidadosamente suas circunstâncias locais antes de adotarem os valores propostos como padrões nacionais ( CETESB, 2011).

No Brasil, o governo do Estado de São Paulo, em 1976, através do decreto estadual $n^{\circ} 8468$, regulamentou alguns padrões para a qualidade do ar. O Conselho Nacional do Meio Ambiente (CONAMA) em 28/06/1990 ampliou esses padrões em âmbito nacional e os transformou em resolução. 
Os padrões de qualidade do ar segundo o Relatório Anual da CETESB em 2011 podem ser divididos em primários e secundários.

Os padrões primários de qualidade do ar são as concentrações de poluentes que, ultrapassadas, poderão afetar a saúde da população. Podem ser entendidos como níveis máximos toleráveis de concentração de poluentes atmosféricos, constituindo-se em metas de curto e médio prazo.

Os padrões secundários de qualidade do ar são as concentrações de poluentes atmosféricos abaixo das quais se prevê o mínimo efeito adverso sobre o bem estar da população, assim como o mínimo dano à fauna e à flora, aos materiais e ao meio ambiente em geral. Podem ser entendidos como níveis desejados de concentração de poluentes, constituindo-se em meta de longo prazo.

A resolução do CONAMA citada acima regulamentou os níveis dos seguintes poluentes: partículas totais em suspensão (partículas com menos de $100 \mu \mathrm{m}$ de diâmetro aerodinâmico), dióxido de enxofre, monóxido de carbono, ozônio, fumaça, partículas inaláveis (com diâmetro aerodinâmico entre 2,5 a $10 \mu \mathrm{m}$ ) e dióxido de nitrogênio (CETESB, 2011).

Porém, a Organização Mundial da Saúde (OMS), recomenda o monitoramento da qualidade do ar, nas grandes cidades, por meio de concentração de $\mathrm{PM}_{2,5}(\mathrm{WHO}, 2005)$ entre outros parâmetros. Além disso, a legislação nacional não define claramente como obter informações suficientes para definir quais são as fontes emissoras, e a falta destes dados dificulta a realização de projetos de políticas públicas voltadas para a melhoria da qualidade do ar (WHO, 2005). 
Os padrões nacionais de qualidade do ar fixados na Resolução CONAMA № 03 de 28/06/90 são apresentados na tabela 1.

Tabela 1: Padrões nacionais de qualidade do ar (Resolução CONAMA № 03 de 28/06/90) (relatório CETESB 2001)

\begin{tabular}{|c|c|c|c|c|}
\hline Poluentes & $\begin{array}{c}\text { Tempo de } \\
\text { Amostragem }\end{array}$ & $\begin{array}{c}\text { Padrão } \\
\text { Primário } \\
\mu \mathrm{g} / \mathbf{m}^{3}\end{array}$ & $\begin{array}{c}\text { Padrão } \\
\text { Secundário } \\
\mu \mathrm{g} / \mathrm{m}^{3}\end{array}$ & Método de Medição \\
\hline \multirow{2}{*}{$\begin{array}{l}\text { Partículas totais em } \\
\text { suspensão }\end{array}$} & 24 horas $^{1}$ & 240 & 150 & \multirow{2}{*}{$\begin{array}{c}\text { Amostradores de grandes } \\
\text { volumes }\end{array}$} \\
\hline & $\mathrm{MGA}^{2}$ & 80 & 60 & \\
\hline \multirow{2}{*}{ Partículas inaláveis } & 24 horas $^{1}$ & 150 & 150 & \multirow{2}{*}{ Separação inercial/filtração } \\
\hline & MAA $^{3}$ & 50 & 50 & \\
\hline \multirow{2}{*}{ Fumaça } & 24 horas $^{1}$ & 150 & 100 & \multirow{2}{*}{ Refletância } \\
\hline & MAA $^{3}$ & 60 & 40 & \\
\hline \multirow{2}{*}{ Dióxido de enxofre } & 24 horas $^{1}$ & 365 & 100 & \multirow{2}{*}{ Pararosanilina } \\
\hline & $\mathrm{MAA}^{3}$ & 80 & 40 & \\
\hline \multirow{2}{*}{ Dióxido de nitrogênio } & 1 hora & 320 & 190 & \multirow{2}{*}{ Quimiluminescência } \\
\hline & MAA $^{3}$ & 100 & 100 & \\
\hline \multirow{4}{*}{ Monóxido de carbono } & 1 hora $^{1}$ & 40.000 & 40.000 & \multirow{4}{*}{ Infravermelha } \\
\hline & & $35 \mathrm{ppm}$ & $35 \mathrm{ppm}$ & \\
\hline & 8 horas $^{1}$ & 10.000 & 10.000 & \\
\hline & & 9ppm & 9ppm & \\
\hline Ozônio & 1 hora $^{1}$ & 160 & 160 & Quimiluminescência \\
\hline
\end{tabular}

- Não deve ser excedido mais que uma vez ao ano.

2 - Média geométrica anual.

3 - Média aritmética anual.

Em diversos países, $0 \quad \mathrm{PM}_{2.5}$ foi sujeito à regulamentação governamental, o que ainda não ocorreu no Brasil, embora seus altos níveis na atmosfera, assim como em outros países, estejam relacionados a efeitos deletérios à saúde (Saldiva et al.,1994; Pope e Dockery, 2006).

Mesmo não existindo no Brasil o padrão de qualidade do ar para $\mathrm{PM}_{2.5}$, estudos mostram que suas concentrações são elevadas quando comparadas a padrões internacionais (McClellan e Jessiman, 2009; CETESB, 2008).

Estudos de longa data já mostraram os efeitos da poluição do ar na saúde humana em vários países (Firket, 1931; Wark et al., 1998; Schwatz, 1999), alguns estudos mostraram que os poluentes gasosos e o material 
particulado inalável $\left(\mathrm{PM}_{10}\right)$ gerados a partir da queima de combustíveis fósseis apresentam efeitos diretos sobre o sistema respiratório, em especial, de crianças e idosos. Esses efeitos têm sido medidos através de aumentos nos atendimentos em pronto-socorros (Lin et al., 1999; Martins et al., 2002; Farhat et al., 2005), internações hospitalares (Dominice et al..2 2006; Medina-Ramon et a.l, 2006) e também por mortalidade (Neas et al., 1999; Braga et al., 2000; conceição et al., 2001).

É de grande importância a caracterização das fontes emissoras da poluição atmosférica, e não apenas nas regiões centrais da RMSP, como vem sendo feito, mas também nas regiões periféricas, pois a composição da poluição pode não ser homogênea em toda a extensão da cidade.

Esta composição pode diferir de acordo com as características sócio econômicas da região, pois pode estar relacionada aos hábitos regionais. Por exemplo, no centro, a poluição atmosférica está intimamente relacionada com a emissão de poluentes veiculares, já na periferia o tráfego não é tão intenso, porém a frota veicular tende a ser mais antiga, com perfil de emissões distinto daquele presente nos veículos mais modernos (Jacob, 2000).

Fontes de emissões não regulamentadas, tais como a queima de lixo domiciliar, ressuspensão de solo e pequenas indústrias são fatores que podem contribuir para que a composição da poluição atmosférica possa variar ao longo da cidade (Jacob, 2000).

O estudo da arquiteta Maria Cristina Haddad Martins (Martins, 2003), mostra que indicadores sócios econômicos modificam significativamente os efeitos da poluição atmosférica sobre indicadores de mortalidade. Por se tratar 
de um estudo ecológico, de séries temporais, não foi possível esclarecer os motivos do maior efeito adverso da poluição em áreas mais desfavorecidas.

Algumas hipóteses podem ser levantadas. É possível que o menor nível sócio econômico aumente a vulnerabilidade aos poluentes pelas condições de saúde dos seus habitantes. Menor acesso aos serviços de saúde; pior manejo de condições crônicas como diabetes, hipertensão e sobrepeso; maior prevalência de fumo; menor possibilidade da compra de medicamentos essenciais são exemplos de condições de maior fragilidade do receptor.

Por outro lado, é possível que as moradias das regiões de menor renda sejam mais "permeáveis" aos poluentes externos, propiciando uma condição de maior exposição. Finalmente, é possível que a qualidade do ar seja pior, veículos com tecnologia mais antiga, a existência de fontes não regulamentadas como as acima mencionadas, podem criar condições de uma pior qualidade do ar.

Neste contexto fica claro a importância de caracterizar o material particulado e suas variações dentro da cidade de São Paulo, pois é possível que a qualidade do ar seja diferente ou pior em regiões ainda não monitoradas. 


\section{Objetivo Geral}

O objetivo deste trabalho foi caracterizar as fontes e analisar os componentes da poluição atmosférica em diferentes regiões dentro da cidade de São Paulo.

\subsection{Objetivos Específicos:}

- Caracterizar as fontes emissoras de $\mathrm{PM}_{2.5}$ em quatro regiões da cidade de São Paulo;

- Analisar os componentes elementares do $\mathrm{PM}_{2.5}$ das quatro regiões amostradas da cidade de São Paulo;

- Verificar a existência de homogeneidade destes componentes nas diferentes regiões amostradas. 


\section{METODOLOGIA}

\subsection{Locais de coleta}

As coletas foram realizadas nos seguintes locais da cidade de São Paulo representados na figura 1.

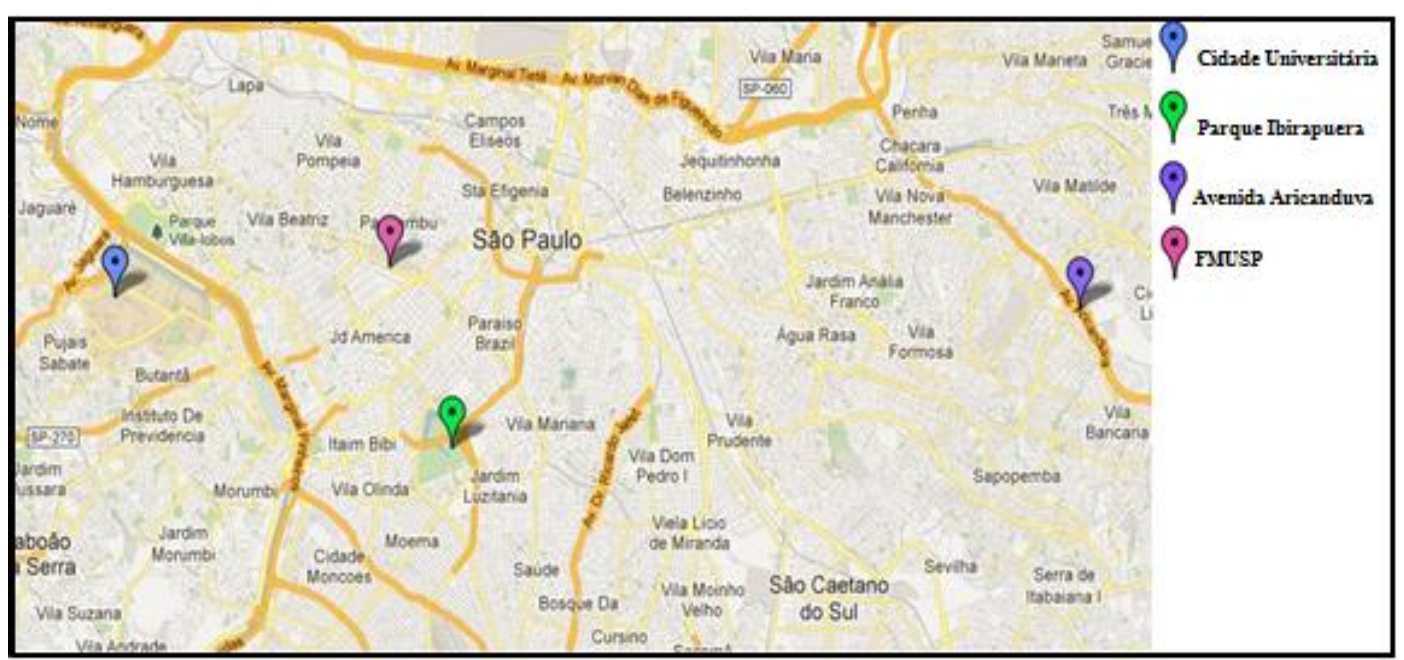

Figura 1: Mapa da Região Metropolitana de São Paulo apontando os quatro locais de amostragem, (fonte: Google maps)

\subsubsection{Faculdade de Medicina da Universidade de São Paulo}

Localizada na região central de São Paulo, local de vias de tráfego intenso, incluindo todas as categorias de combustíveis. As amostras foram coletadas próximas da Avenida Dr. Arnaldo, 455 nas coordenadas (233' $14.48^{\prime \prime}$ S e $46^{\circ} 40^{\prime} 15.82^{\prime \prime}$ O). 


\subsubsection{Cidade Universitária}

O maior Campus da Universidade de São Paulo fica na região oeste da cidade, encontra-se próxima a importantes vias de trafego intenso, por exemplo, a Avenida escola Politécnica, Avenida Marginal Pinheiros, Avenida Corifeu de Azevedo Marques e a Rodovia Raposo Tavares. As amostras foram coloetadas no telhado do (Instituto de Astronomia, Geofísica e Ciências Atmosfericas (IAG), coordenadas (233"33.22" S e 46²4'00.71" O).

3.1.3 Zona Leste (próximo Avenida Aricanduva, 5500)

Na região leste da cidade de São Paulo as amostras foram coletadas a aproximadamente 400 metros da Avenida Aricanduva, 5500. Esta é uma importante avenida da região leste, com grande fluxo de veículos incluindo todas as categorias de combustíveis, nas coordenadas $\left(23^{\circ} 33^{\prime} 45.46 " \mathrm{~S}\right.$ e $\left.46^{\circ} 30^{\prime} 43.21^{\prime \prime} \mathrm{O}\right)$ 


\subsubsection{Parque do Ibirapuera}

$\mathrm{Na}$ região sul de são Paulo as amostras foram coletadas dentro do Parque do Ibirapuera. Importante parque da cidade de São Paulo, circundado por vias de tráfego intenso, avenida republica do Líbano, Avenida Vinte e Três de Maio, e Avenida Pedro Álvares Cabral. E ainda próximo ao aeroporto de Congonhas, coordenadas $\left(23^{\circ} 35^{\prime} 30.40^{\prime \prime} \mathrm{S}\right.$ e $\left.46^{\circ} 39^{\prime} 38.24^{\prime \prime} \mathrm{O}\right)$.

\subsection{Metodologia de Amostragem}

Para compreender um pouco melhor a complexa atmosfera da cidade de São Paulo, foram feitas coletas não apenas no centro urbano, mas também em regiões periféricas onde a poluição pode ter características diferentes das regiões centrais da cidade.

Para isso foram realizadas coletas de material particulado em quatro locais diferentes dentro da cidade de São Paulo, organizadas em duas campanhas de vinte dias cada, a primeira no inverno (inicio de setembro) de 2011 e a segunda no verão (dezembro) de 2011.

Em todas as campanhas o material particulado foi coletado em filtros de policarbonato (Millipore $\AA$, com $37 \mathrm{~mm}$ de diâmetro, e 0,8 $\mu \mathrm{m}$ de porosidade), utilizando amostradores Harvard (HI, Air Diagnostics and Engineer Inc., Harrisson, ME). Os filtros foram expostos por 24 horas em dias subsequentes 
e após exposição foram submetidos a distintas técnicas analíticas para determinação da massa amostrada e subsequente cálculo da concentração (gravimetria), para determinação da concentração de Black carbon (refletância) e para a composição e concentração elementar do $\mathrm{PM}_{2.5}$ amostrado (fluorescência de RX).

\subsubsection{Amostrador de Particulado Fino}

O equipamento utilizado para coleta de $\mathrm{PM}_{2,5}$ foi $\mathrm{O}$ amostrador de particulado fino construído na Universidade de Harvard (HI), EUA. Este equipamento coleta PM em suspensão no ar com diâmetro aerodinâmico menor ou igual a 2,5 $\mu \mathrm{m}$. O amostrador consiste de um coletor de ar de baixo volume, composto por um impactador (figura 2), uma bomba a vácuo, um sistema de regulagem e medição de vazão de ar, e um coletor de PM (filtro) onde este restringe a passagem de PM maior que 2,5 $\mu \mathrm{m}$ (esquema de impactação ilustrado na figura 3).

O filtro utilizado foi previamente pesado no laboratório em uma balança analítica ultrassensível (UMX2, da Mettler \& Toledo, Suiça).

O filtro é colocado na seção de coleta de pó, para que a bomba de vácuo possa regularizar a vazão do sistema. São registrados o volume e a vazão do ar. Assim, pode-se obter da diferença entre a pesagem inicial e final normalizada pelo volume de ar a concentração média de material particulado coletado no período. O conjunto (figura 4) (amostrador, bomba, horímetro, sondas e caixa) foi desenvolvido no nosso Laboratório. 


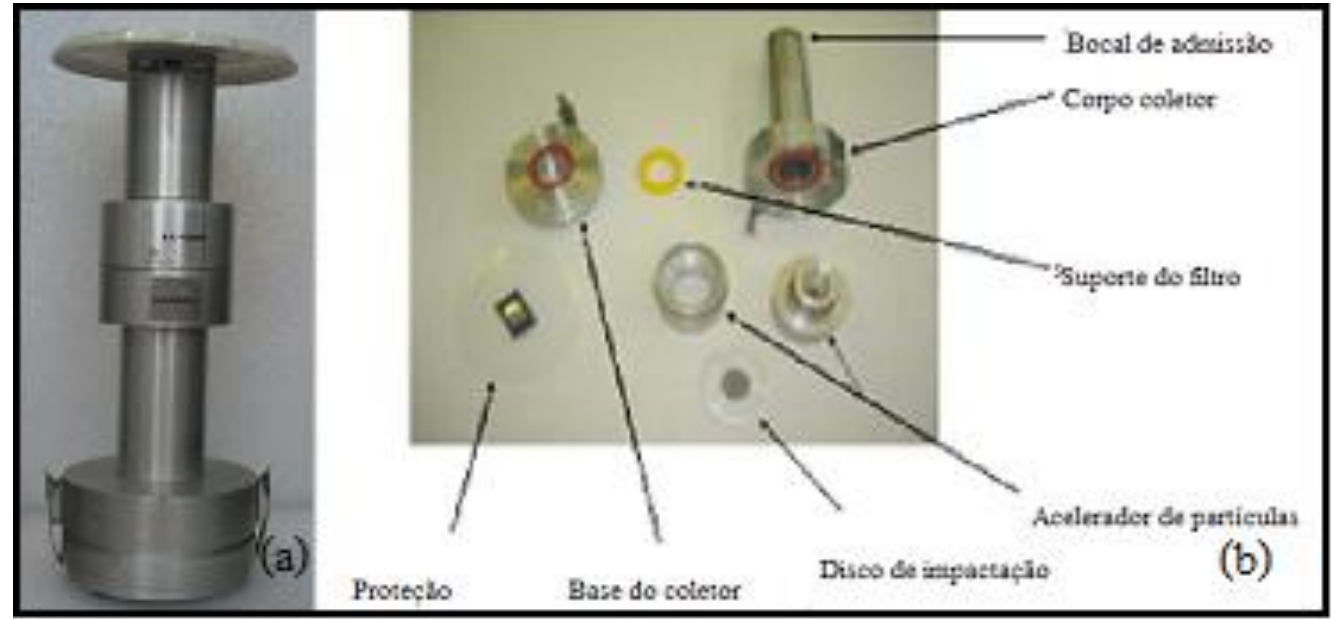

Figura 2: (a) vista geral do impactador; (b) vista das partes que constituem o impactador (LPAE et al., 2009).

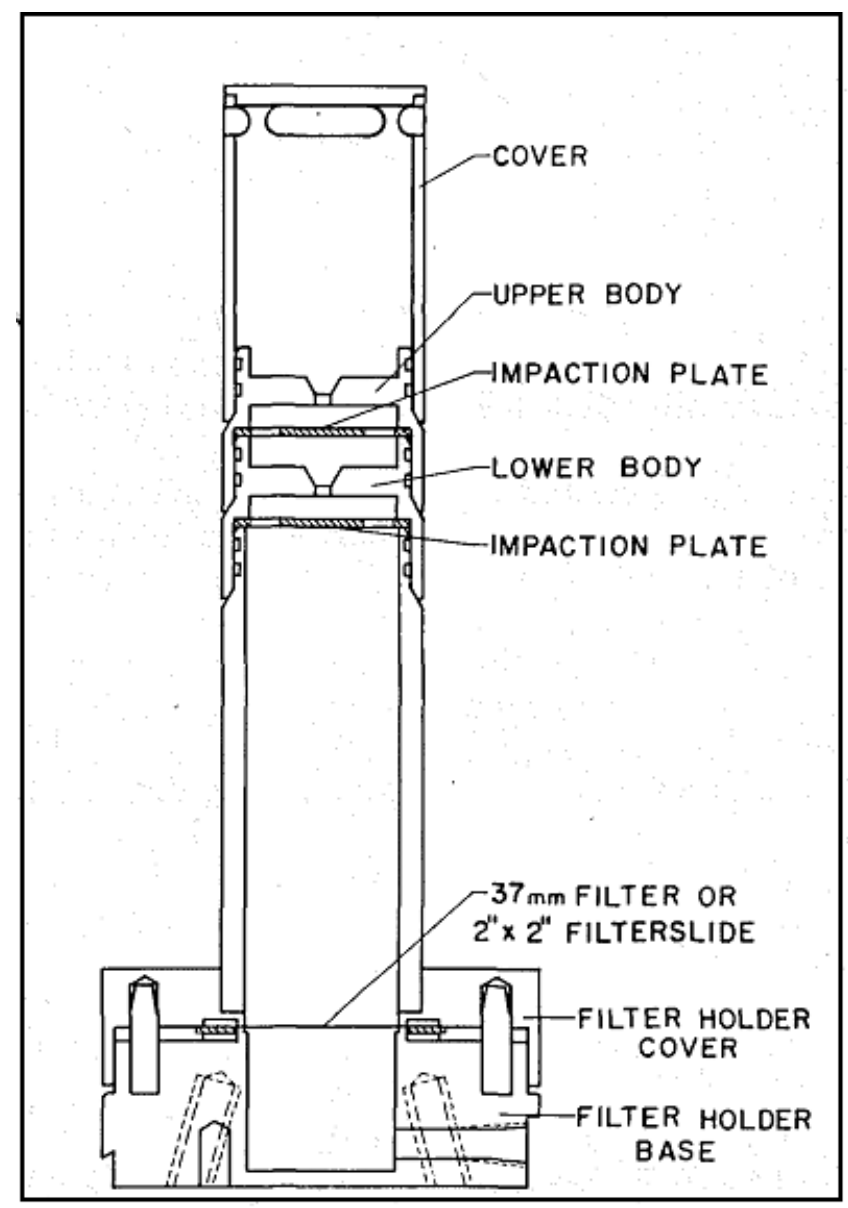

Figura 3: Ilustração do sistema de impactação.

Imagem retirada do artigo de William Turner e John D. Spengler,(1987) 


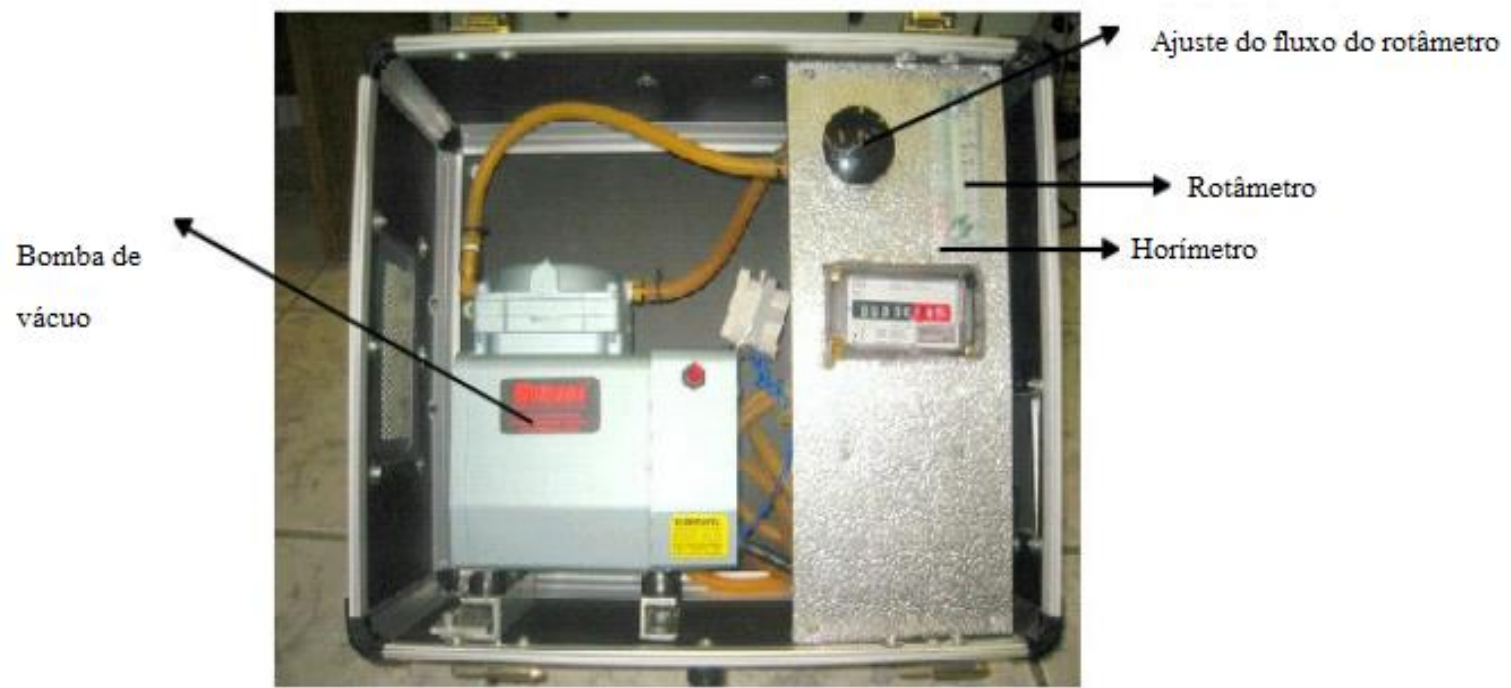

Figura 4: Conjunto:Bomba de vácuo, rotâmetro, ajuste de fluxo de rotâmetro, horímetro) (LPAEet al., 2009)

\subsubsection{Filtros}

O material particulado foi coletado em filtros de policarbonato (Millipore ${ }^{\circledR}$, com $37 \mathrm{~mm}$ de diâmetro, e $0,8 \mu \mathrm{m}$ de porosidade), os filtros são colocados em discos de proteção para que fiquem encaixados dentro do impactador,a figura 5 mostra o filtro antes(b) e depois(a) da coleta de $\mathrm{PM}_{2.5,}$ e os discos de proteção.

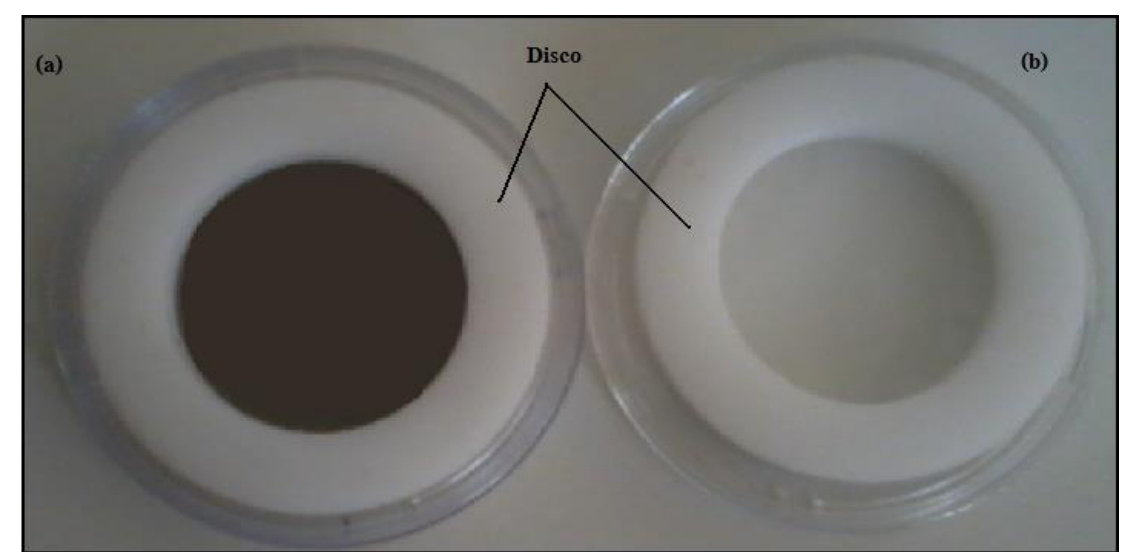

Figura 5: Disco com filtro de policarbonato (Millipore $\AA$, com $37 \mathrm{~mm}$ de diâmetro, e $\quad 0,8$ $\mu \mathrm{m}$ de porosidade); (a) filtro após exposição, (b) filtro antes da exposição. 


\subsubsection{Balança e Descarregador Eletrostático}

Para a análise de gravimetria foi utilizada uma balança analítica ultrassensível (UMX2, da Mettler \& Toledo, Suiça) (Figura 6) na qual os filtros foram pesados antes e após a exposição. Foi utilizado também um descarregador eletrostático Ionizer Antistatic Systems da METTLER/TOLEDO (figura 7), no qual os filtros foram descarregados eletrostaticamente antes de cada pesagem para melhores resultados.

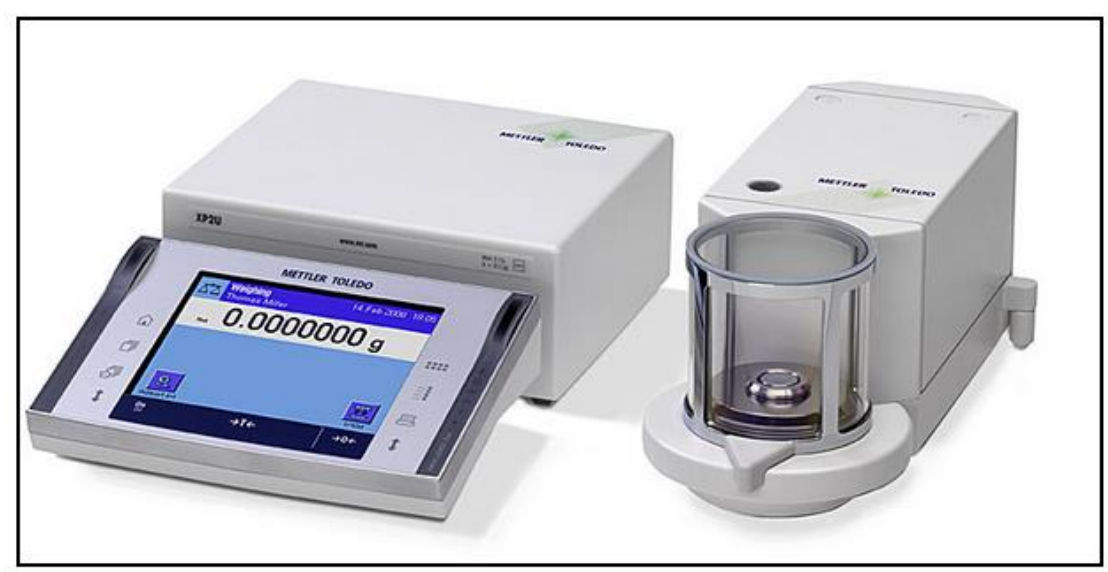

Figura 6: Balança ultrassensivel UMX2, da Mettler \& Toledo, Suiça (http://br.mt.com)

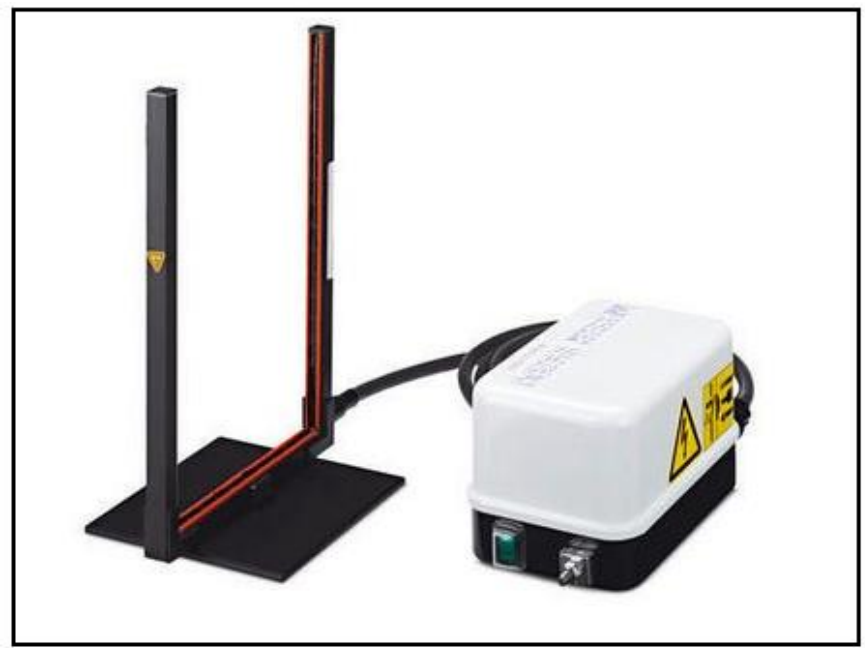

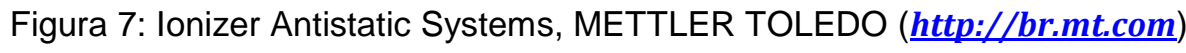




\subsubsection{Refletômetro}

Foi utilizada um Refletômetro, marca "Diffusion Systems Ltd." modelo "Smoke Stain reflectometer- Model 43" ilustrado na figura 8 para a determinação das concentrações de Carbono Elementar(BC).

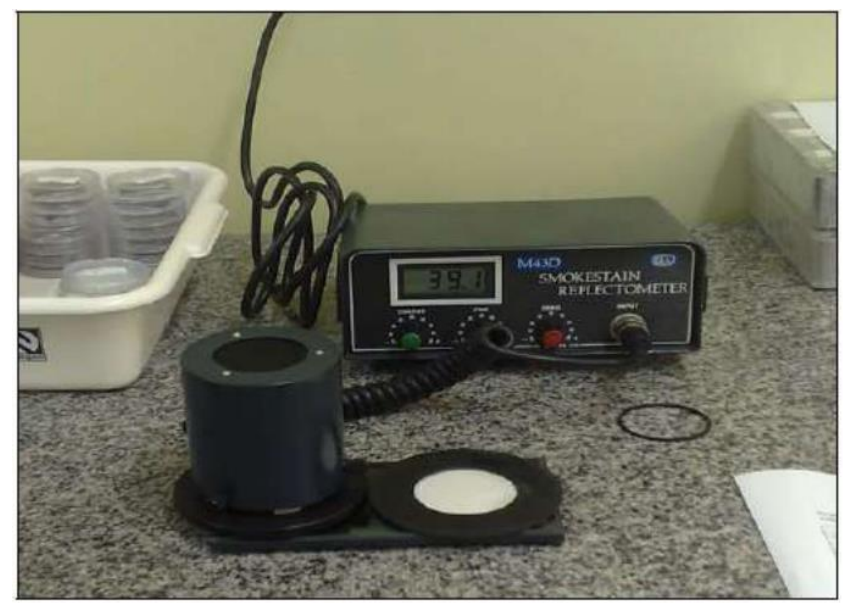

Figura 8: Refletômetro.

\subsubsection{Fluorescência de Raio-X}

Para a Determinação de fluorescência de raio $X$ foi utilzado o equipamento (Shimatzu Modelo Espectrômetro Rigaku, RIX 300) (figura 9) que localiza-se no Laboratório de Análises de Processos Atmosféricos (LAPAt).

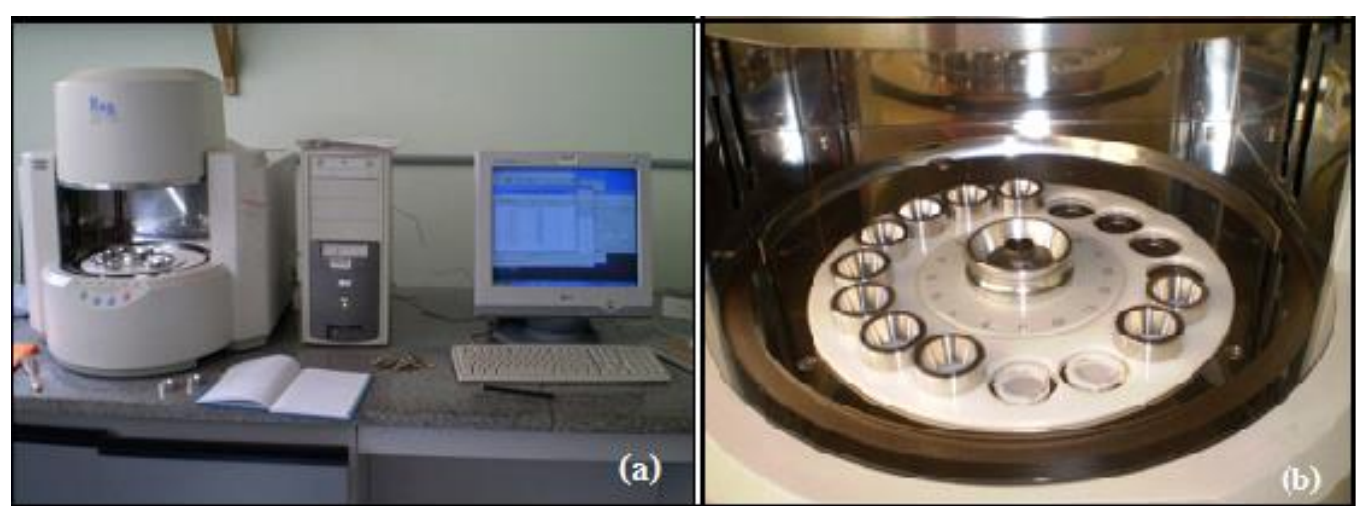

Figura 9: (a) vista geral do RIX-300, (b) detalhe, mostrando o disco onde as amostras são colocadas para análise. 


\subsection{Metodologia Analítica}

\subsubsection{Medidas Gravimétricas}

A determinação da massa de partículas depositadas nos filtros de policarbonato foi feita pelo método gravimétrico, ou seja, diferença entre os pesos antes e depois da exposição. Os filtros foram condicionados por um período de 24 horas em ambiente controlado com temperatura constante de $25^{\circ} \mathrm{C} \pm 1$ e a umidade relativa de $60 \% \pm 3$ antes e depois de cada pesagem. Foi Utilizada uma balança analítica ultrassensível (UMX2, da Mettler \& Toledo, Suiça). Para melhor resultado, antes de cada pesagem, os filtros passaram por um descarregador eletrostático (Ionizer Antistatic Systems, METTLER TOLEDO). Para determinação da concentração de $\mathrm{PM}_{2.5}$ a massa depositada de cada filtro foi dividida pelo volume de ar da amostragem do mesmo.

\subsubsection{A determinação da concentração de Black Carbon por refletância}

Para determinação das concentrações de carbono elementar ("Black Carbon" - BC) presentes nas amostras, foi utilizada a técnica de refletância de luz, com um Refletômetro, marca "Diffusion Systems Ltd." modelo "Smoke Stain reflectometer- Model 43". 
A técnica de refletância consiste na incidência de luz de uma lâmpada de Tungstênio no filtro amostrado, que reflete uma intensidade inversamente proporcional à quantidade de BC presente (Yamasoe, 1994). Como as partículas de BC são boas absorvedoras de luz, quanto maior a sua presença, menor a intensidade de luz refletida pelo filtro e menor a detectada pelo fotosensor. A concentração de Black Carbon é dada pela equação abaixo:

$$
\begin{gathered}
[\mathrm{BC}]=((81,95-(71,83 * \log (R)))+15,43 *(\log (R)) 2) * A) /(V) \\
\text { Onde: }
\end{gathered}
$$

\subsubsection{Determinação da composição elementar por Fluorescência de Raio-X}

Esta técnica é de grande importância na análise multi-elementar em amostras oriundas de sistemas biológicos, pois pode determinar tanto macro elementos como Cálcio $(\mathrm{Ca})$ e Potássio $(\mathrm{K})$, como elementos traços, como Cobre $(\mathrm{Cu})$ e Chumbo $(\mathrm{Pb})$, ou também de elementos não-metais como Enxofre (S) (Richardson, 1995).

Outra característica de relevante importância é que esta é uma técnica não destrutiva, assim, a amostra depois de analisada pode ser arquivada para 
futuras análises, tornando este método ideal para análises periódicas de estudos de monitoramento de atividades industriais (Richardson et al.1992).

$\mathrm{Na}$ análise de FRX têm-se três fases: excitação dos elementos que constituem a amostra, dispersão dos raios $\mathrm{X}$ característicos emitidos pela amostra, detecção desses raios.

Desse modo ao se considerar as intensidades (número de raios $\mathrm{X}$ detectados por unidade de tempo) dos raios $\mathrm{X}$ característicos emitidos pela amostra (IAEA, 1970), obtemos linhas espectrais com energias características de cada elemento, onde a intensidade está relacionada à concentração do elemento na amostra. A concentração de cada elemento é, normalmente, expressa em termos de massa desse elemento dividido pela massa total da amostra, sendo habitualmente expressa em \% ou em $\mathrm{mg} / \mathrm{g}$.

O equipamento utilizado (Shimatzu Modelo Espectrômetro Rigaku, RIX 300) localiza-se no Laboratório de Análises de Processos Atmosféricos (LAPAt).

Para esse procedimento, foram recortados um quarto de cada filtro e colados em um anel de teflon. Os resultados obtidos dessa análise foram convertidos às concentrações de cada elemento identificado pelo programa WinQXAS (Windows Quantitative X-ray Analysis System), por meio de ajuste de linhas espectrais. Em geral a FRX não possibilita um quantificação absoluta da concentração elementar, por isso foi realizado um procedimento em que alvos de calibração e características do sistema no programa WinQXAS foram utilizados, possibilitando a quantificação elementar em massa por volume de ar amostrado. 


\subsection{Estatísticas}

Os resultados deste estudo foram resumidos por meio da construção de tabelas contendo os valores das estatísticas descritivas como: médias, desvio padrão e medianas. Para a visualização dos resultados também foram construídos gráficos de caixa (Box-plots) e de barras.

As medias das concentrações da massa de $\mathrm{PM}_{2.5}$ e de $\mathrm{BC}$ foram comparados entre as estações do ano e entre as regiões amostradas.

Foi realizada uma Analise de Fatores utilizando o programa SPSS com o objetivo de construir índices que possam determinar a contribuição de diferentes fontes de emissão.

Foi fixado nível de significância de $5 \%$ em todos os testes de hipótese. 


\section{Resultados e Discussão}

\subsection{Análises gravimétricas}

Os filtros coletados foram pesados antes e depois da exposição, e foram determinados os valores da diferença entre as pesagens (massa de deposição de $\mathrm{PM}_{2.5}$ ). Foi elaborado o gráfico (Box-plots) da Figura 10 mostrando as variações da concentração de $\mathrm{PM}_{2.5}$ encontradas entre os locais de coleta $\mathrm{e}$ também entre o período de amostragem nas estações de Inverno e Verão.

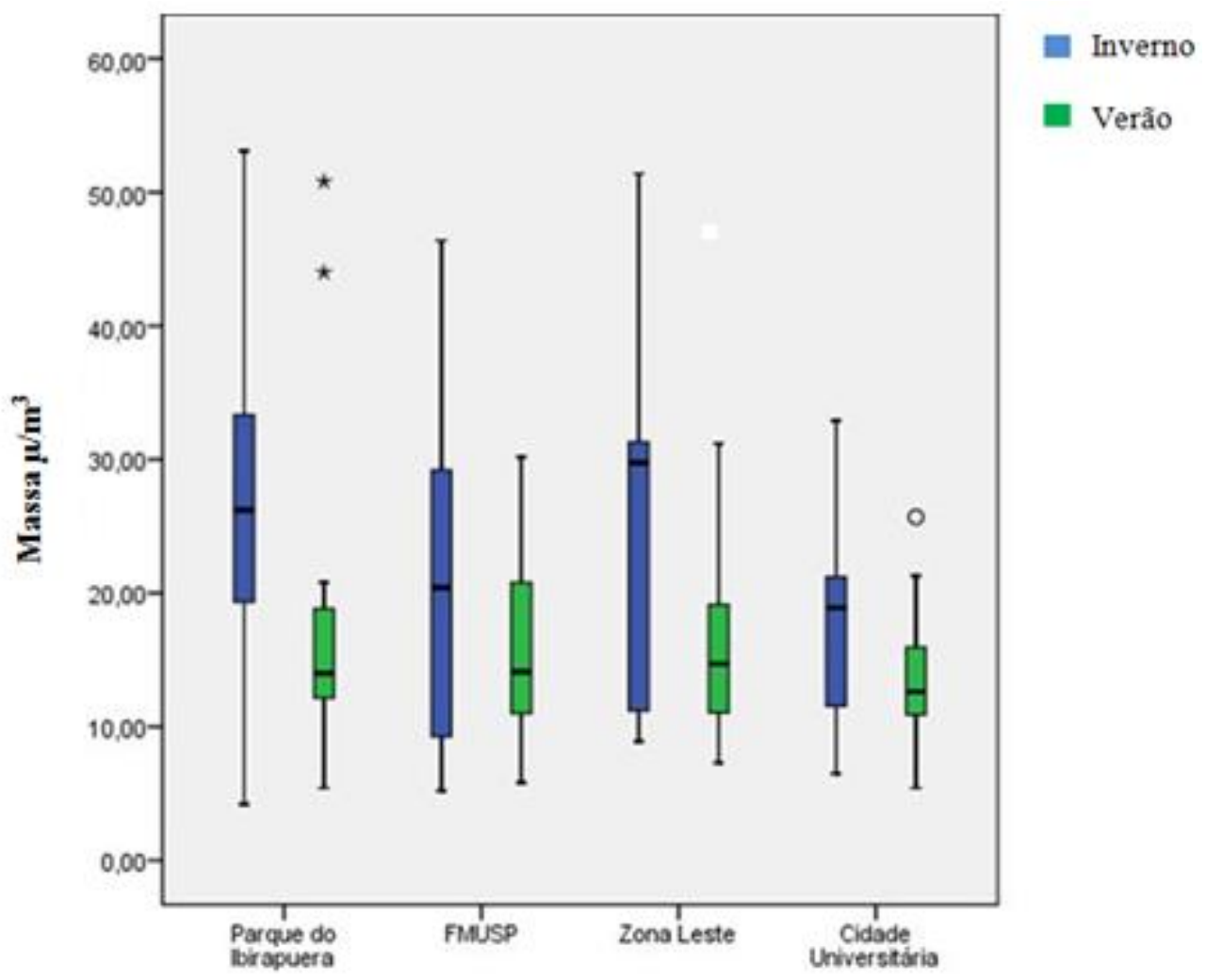

Figura10: Variação da concentração da massa de $\mathrm{PM}_{2.5}$ nos períodos de inverno de $2011 \mathrm{e}$ verão de 2011 para cada local amostrado. 
Podemos notar que a concentração da massa de $\mathrm{PM}_{2.5}$ foi maior nas amostras coletadas durante o período de inverno em todos os locais amostrados. Este resultado corrobora com estudo recente realizado em seis capitais brasileiras, inclusive em São Paulo, no qual monitorou os niveis de $\mathrm{PM}_{2.5}$ em locais com alto tráfego (Miranda et al., 2010). Outros estudos também encontraram resultados semelhantes aos deste trabalho (Castanho e Artaxo, 2001; Miranda et al., 2002).

O inverno de São Paulo é caracterizado por apresentar baixa taxa de precipitação (Instituto Nacional de Meteorologia) e diminuição da eficiência dos processos que reduzem a quantidade de $\mathrm{PM}_{2.5}$ pela umidade, chamado remoção úmida (CETESB, 2009).

A Organização Mundial de Saúde (OMS) afirma que a concentração média anual de $\mathrm{PM}_{2.5}$ deve estar abaixo de $10 \mu \mathrm{g} / \mathrm{m}^{3}$, não podendo apresentar picos maiores que $25 \mu \mathrm{g} / \mathrm{m}^{3}$, o presente estudo mostra que tanto no verão quanto no inverno o nivel de concentração de $\mathrm{PM}_{2.5}$ ficou acima dos parâmetros considerados seguros à saúde recomendado pela OMS. A regulamentação para o material particulado já ocorre em alguns países, o que ainda não ocorreu no Brasil, apesar de muitos estudos relacionarem altos níveis de $\mathrm{PM}_{2.5}$ na atmosfera a efeitos prejudiciais à saúde.

Estes achados são preocupantes porque $0 \mathrm{PM}_{2.5}$ pode penetrar no nosso organismo até os alvéolos pulmonares, portanto, além do desconforto respiratório pode intensificar doenças como a asma e problemas cardíacos (Saldiva et al., 1994; Lanki et al., 2006; Stolzel et al., 2007), o $\mathrm{PM}_{2.5}$ também está associado a aumento do número de internações hospitalares (Braga et 
al., 2001) e mortalidade (Freitas et al., 2004; Lacasana et al., 2005;Ostro et al., 2006).

\subsection{Análise de Refletância}

Após a análise gravimétrica foi calculada a concentração de $B C$ através da técnica de refletância. $\mathrm{O}$ gráfico da Figura 11 apresenta a variação das concentrações de BC encontradas nas amostras coletadas durante o período de amostragem no inverno de 2011 e verão de 2011 nos quatro locais amostrados.

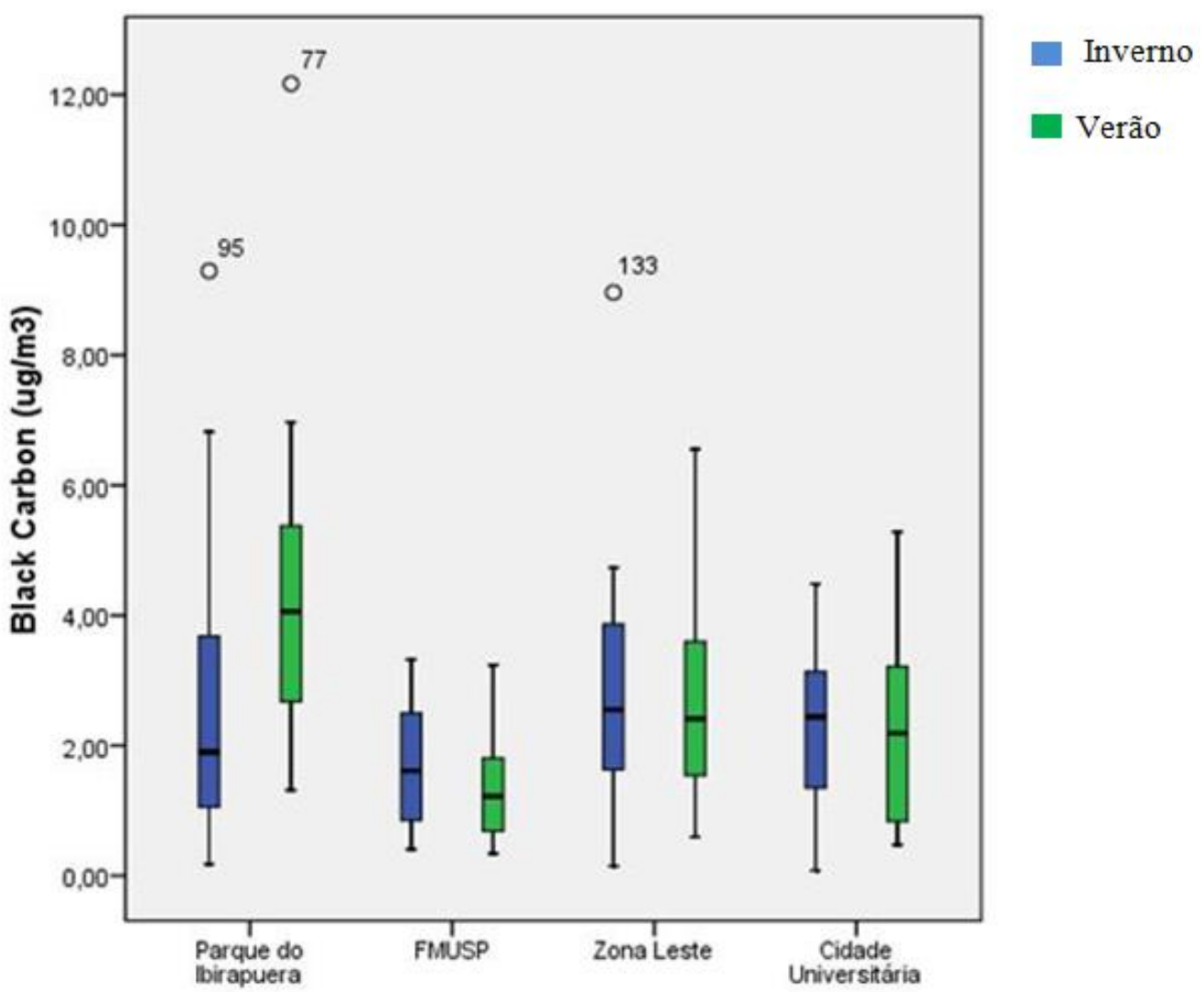

Figura 11: Variação da concentração de Black Carbon obtida pela técnica de refletância durante os períodos de inverno de 2011 e verão de 2011 para cada local amostrado. 
Nota-se que as concentrações de BC não apresentam diferença significativa entre as amostras coletadas no Inverno e Verão em todas as regiões amostradas. Porém, na região do Parque do Ibirapuera a concentração mediana das amostras coletadas no Verão é maior do que a concentração verificada nas amostras coletadas no Inverno. Esse resultado não corrobora com estudos anteriores (Castanho e Artaxo 2001; Miranda et al., 2004) nos quais afirmam que as concentrações de BC são maiores durante o inverno.

Comparando as regiões amostradas, verifica-se que as maiores concentrações foram encontradas nas regiões do Parque do lbirapuera e Zona Leste, locais de amostragens próximos a grandes corredores de tráfego (Parque do Ibirapuera - Corredor Norte-Sul e Avenida dos Bandeirantes; e na zona Leste - Avenida Aricanduva) e com alto fluxo de veículos pesados, que vai de encontro com os resultados de estudos que afirmam que o $B C$ é emitido majoritariamente nos processos de combustão e em especial durante a queima de diesel por veículos pesados (Watson et al., 2002; Martins et a.l, 2006; Sanchez-Ccoyllo et al., 2008; Castanho, 1999).

Apesar da Cidade universitária também se encontrar próxima a importantes vias de grande tráfego; Av. Escola Politécnica, Marginal Pinheiros, Av. Corifeu de Azevedo Marques e da Rodovia Raposo Tavares; apresentou concentrações de BC menores que as das regiões leste e sul, provavelmente devido ao local de coleta, sobre o telhado do edifício (15 metros). A dispersão de poluentes é determinada por vários processos. Um dos processos é a advecção do poluente pelo vento. A velocidade do vento aumenta com a altura, sendo assim, quanto maior a altura em que se encontra o poluente mais ele será disperso. (Cataldi et al, 2000; Veleda, 2001). 


\subsection{Análise comparativa}

Observamos que o Parque do Ibirapuera apresenta uma situação diferenciada. A Figura 12 mostra a porcentagem de BC presente no total de $\mathrm{PM}_{2.5}$ coletado no Parque nas diferentes estações do ano.

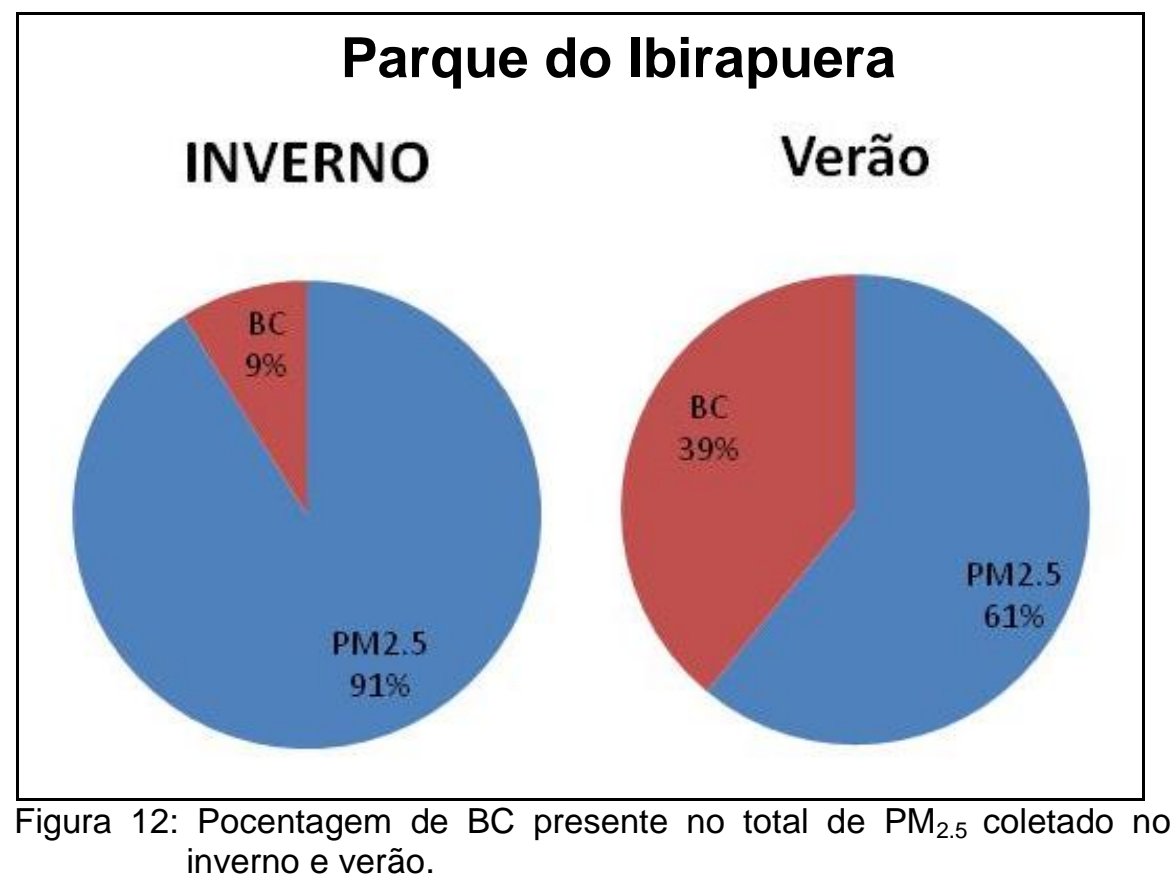

Nota-se que a contribuição de BC no parque é maior nas amostras coletadas no verão do que nas amostras coletadas no inverno, resultado este que não corrobora com estudos anteriores (Castanho e Artaxo 2001; Miranda et al. 2004). Este resultado chamou a atenção e foi feita uma pesquisa sobre o que poderia ter influenciado esse aumento. 
Uma hipótese levantada foi que o aumento da concentração de BC das amostras coletadas no verão do Parque do Ibirapuera podem ter sido influenciadas por emissões de combustíveis de aviões comerciais. Este local de coleta é o único que se encontra próximo a um aeroporto (Aeroporto de Congonhas), pesquisando sobre emissão de Material Particulado por combustível de avião foram encontrados estudos que mostram que o BC é emitido em grande quantidade por motores de aviões comerciais (Kinsey e Hays, 2011). Sabendo desta informação foi pesquisado o número de vôos realizados no aeroporto de congonhas durante os meses de amostragem.

No inverno as coletas foram realizadas no começo de setembro, e o numero de vôos neste mês foi de 156.095. No verão as coletas foram realizadas no mês de dezembro e o número de vôos registrados neste mês foi de 209.280, mostrando que o número de aeronaves durante o mês de coletas no verão foi aproximadamente $25 \%$ maior que no período das coletas do inverno (INFRAERO).

Diversos autores descrevem casos de doenças respiratórias, neurológicas, oculares, auditivas, dermatológicas e ligadas ao sistema hematopoiético em aeroportos (Ritchie, 2003, 2004; Tunnicliffe, 1999; Carlton, 2000; Kobayashi et al., 2000; Miyamoto 1986). Neste contexto existe a possibilidade de que a população que freqüenta o Parque do Ibirapuera possa estar exposta as emissões de combustíveis tanto de veículos automotores quanto de aviões comerciais. 


\subsection{Análise elementar}

Após os filtros serem analisados pelas técnicas de gravimetria e refletância, foi feita a Fluorescência de Raios-X, com este técnica foi possível calcular a concentração dos elementos $(\mathrm{Na}, \mathrm{Mg}, \mathrm{Al}, \mathrm{Si}, \mathrm{P}, \mathrm{S} \mathrm{Cl}, \mathrm{K}, \mathrm{Ca}, \mathrm{Ti}, \mathrm{V}$, $\mathrm{Cr}, \mathrm{Mn}, \mathrm{Fe}, \mathrm{Ni}, \mathrm{Cu}, \mathrm{Zn}, \mathrm{Se}, \mathrm{Br}$ e Pb) em cada amostra. Após calcular a média das concentrações foram elaborados gráficos mostrando as concentrações médias de cada elemento para os locais amostrados no período de coletas nos meses de verão e inverno.

As figuras $13,14,15$ e 16 mostram, respectivamente, os gráfico das concentrações médias de cada elemento encontradas nas coletas realizadas durante verão e inverno para a Cidade Universitária, FMUSP, Parque do Ibirapuera e Zona Leste. Para o elemento enxofre foi feito um gráfico da media das concentrações das amostras coletadas nos períodos de inverno e verão nas quatro regiões estudadas (figura 17) separadamente para melhor visualização, pois sua concentração foi consideravelmente maior que as concentrações dos outros elementos dificultando a visualização dos elementos com baixa concentração. 


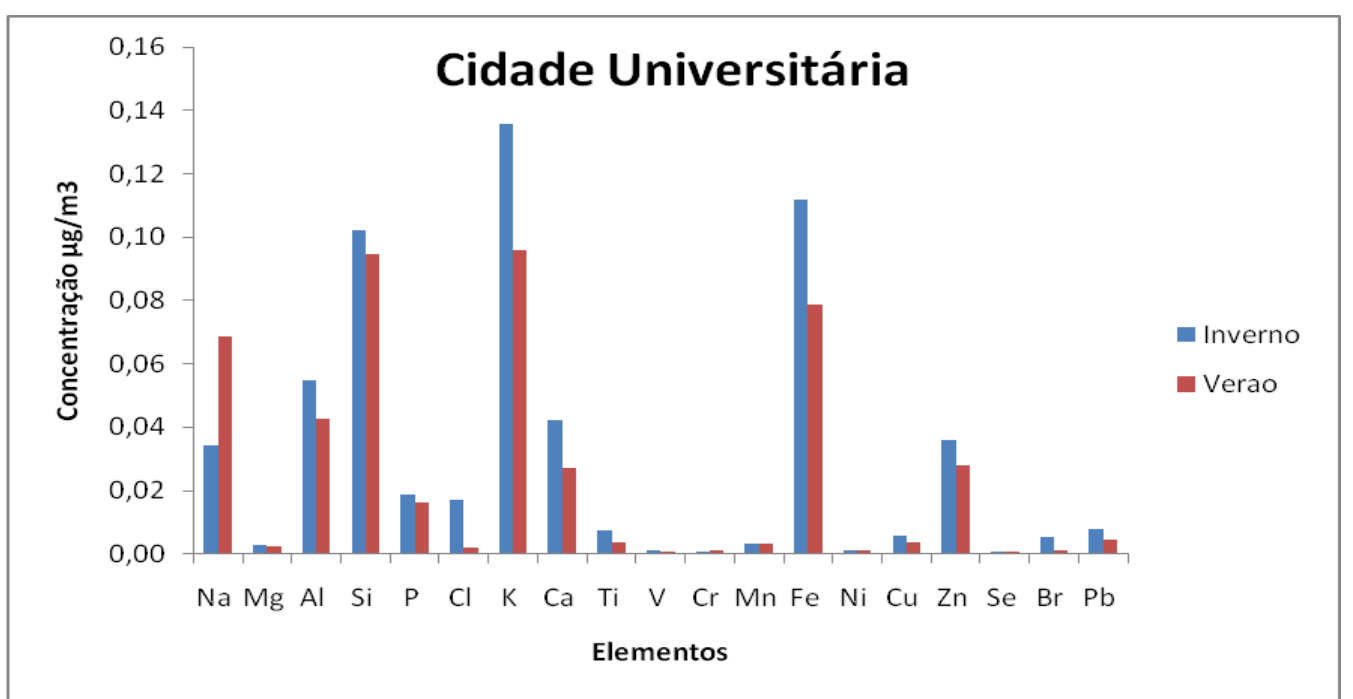

Figura 13: Concentrações medias dos elementos encontrados nas amostras coletadas nos períodos de inverno e verão na Cidade Universitária

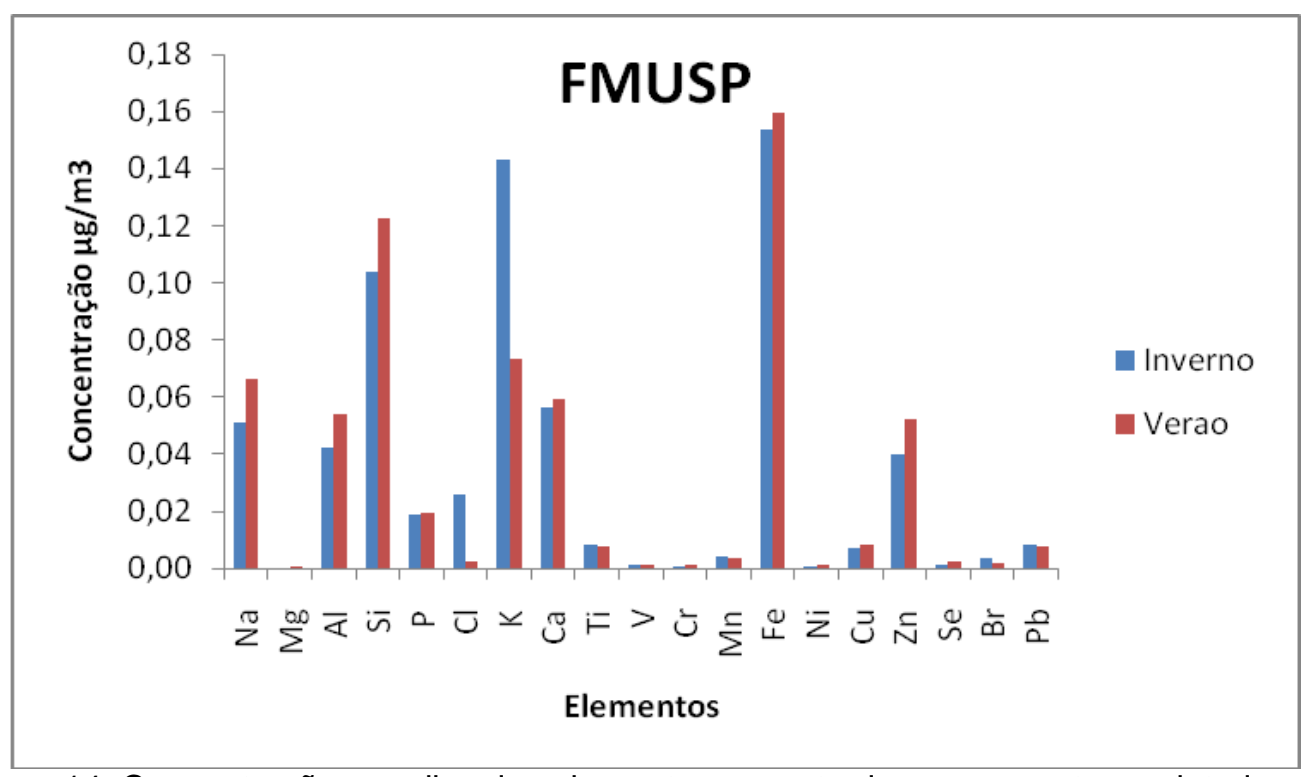

Figura 14: Concentrações medias dos elementos encontrados nas amostras coletadas nos períodos de inverno e verão na FMUSP. 


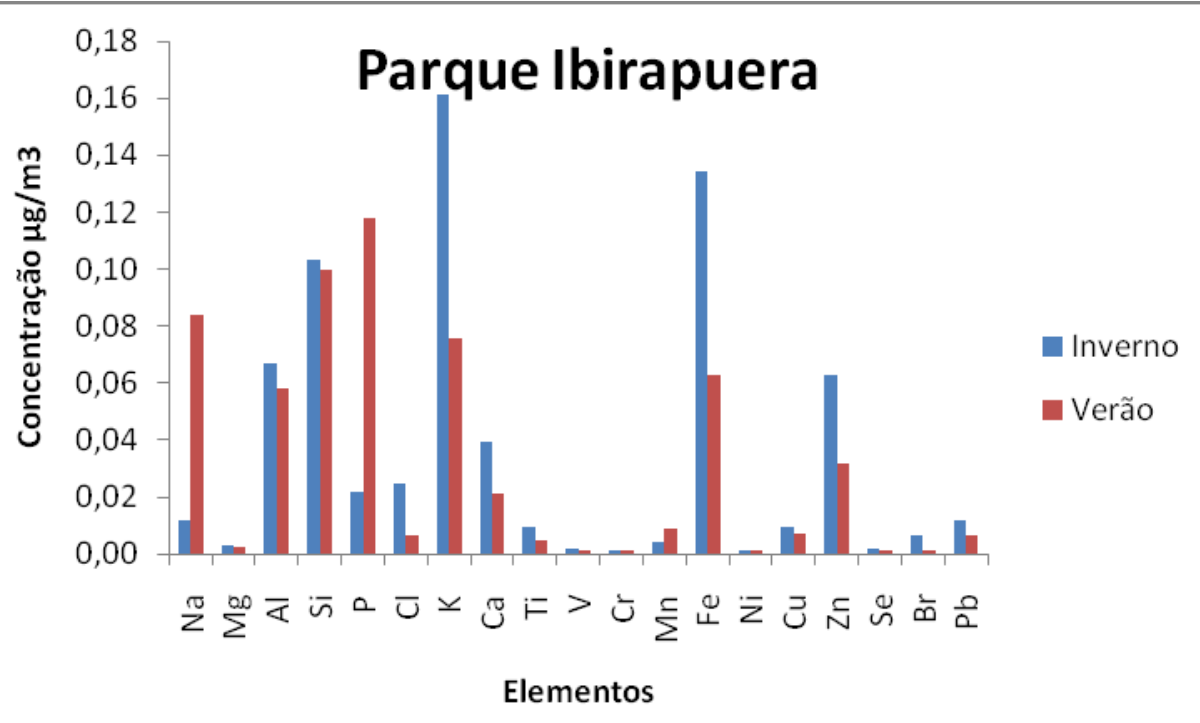

Figura 15: Concentrações medias dos elementos encontrados nas amostras coletadas nos períodos de inverno e verão no Parque Ibirapuera.

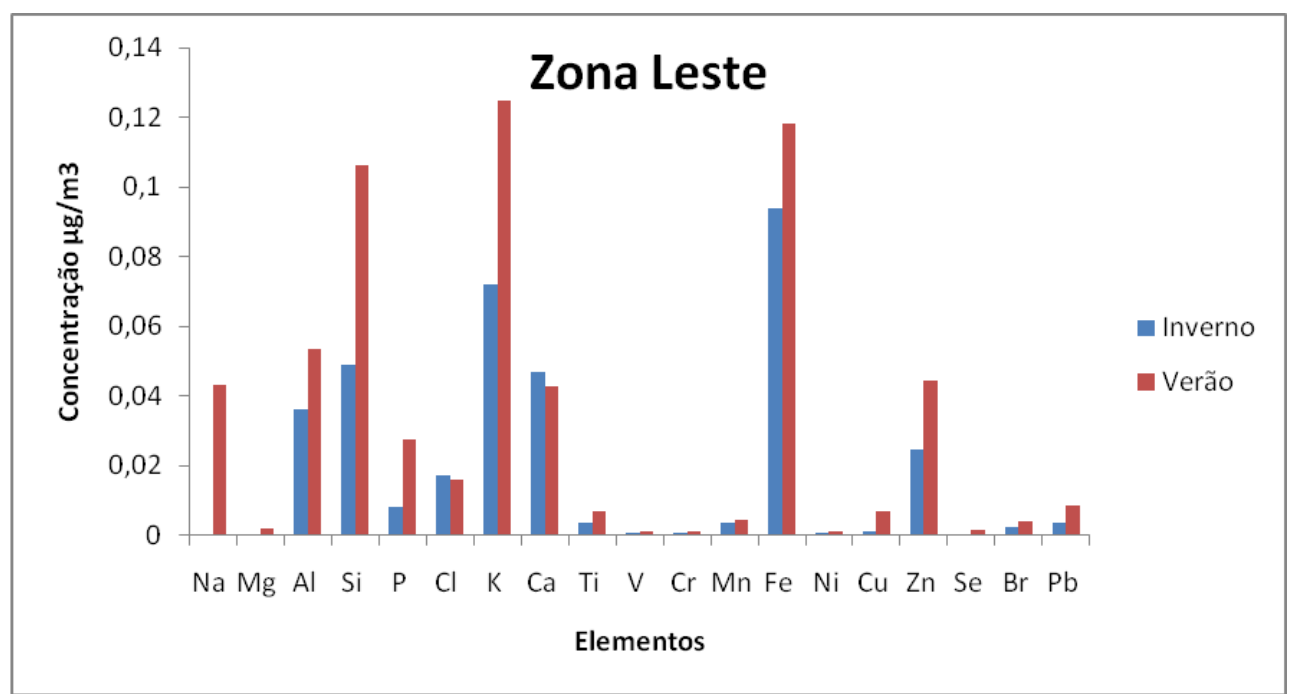

Figura 16: Concentrações medias dos elementos encontrados nas amostras coletadas nos períodos de inverno e verão na Zona Leste. 


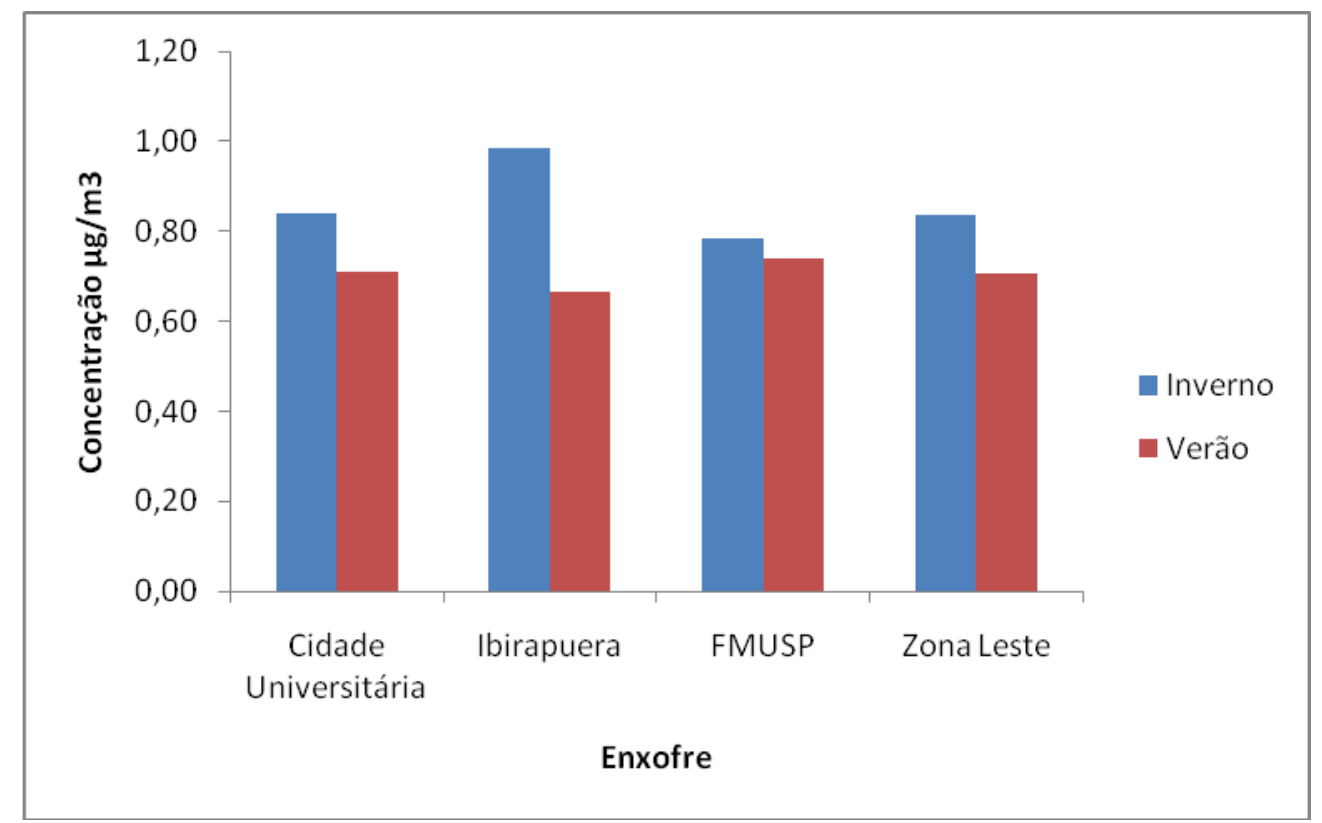

Figura 17: Medias das concentrações de Enxofre encontradas nas amostras coletadas nos períodos de inverno e verão nas quatro regiões estudadas.

Nota-se que o enxofre (S), elemento-traço marcador de queima de combustível fóssil (CETESB, 2006), foi encontrado em maior quantidade que os outros elementos em todos os locais amostrados, mostrando que provavelmente as emissões veiculares são grandes fontes poluidoras em todas as regiões estudadas.

Com o objetivo de tentar identificar as fontes a partir dos dados das concentrações, foi realizada a Análise de Fatores.

Este tipo de análise já foi utilizada para a caracterização do material particulado em outros estudos tais como, Castanho e Artaxo (2001), SanchezCcoyllo e Andrade (2002), Albuquerque (2005); Oliveira (2007) e Andrade et al (2010).

No presente trabalho foram encontrados 3 fatores que conseguiram explicar mais de $75 \%$ da variância total dos dados representados na tabela 2 . 
Os valores em negrito indicam as maiores contribuições (acima de 0,5), que possibilitaram a identificação das fontes.

Tabela 2: Elementos $\left(\mathrm{em} \mu \mathrm{g} / \mathrm{m}^{3}\right)$ e fatores.

\begin{tabular}{cccc}
\hline ELEMENTOS & \multicolumn{2}{c}{ FATORES } \\
\cline { 2 - 4 } $\mathbf{T i}$ & $\mathbf{1}$ & $\mathbf{2}$ & $\mathbf{3}$ \\
$\mathbf{V}$ & $\mathbf{0 , 8 2 6}$ & $-0,356$ & $-0,084$ \\
$\mathbf{M n}$ & $\mathbf{0 , 8 8 9}$ & $\mathbf{0 , 5 1 1}$ & $-0,17$ \\
$\mathbf{F e}$ & $\mathbf{0 , 8 9 6}$ & $-0,31$ & 0,045 \\
$\mathbf{N i}$ & $\mathbf{0 , 5 8 7}$ & $-0,274$ & $-0,133$ \\
$\mathbf{P b}$ & $\mathbf{0 , 7 5 8}$ & 0,214 & $\mathbf{0 , 5 0 0}$ \\
$\mathbf{P}$ & $\mathbf{0 , 7 3 2}$ & $\mathbf{0 , 5 3 3}$ & $-0,101$ \\
$\mathbf{B C}$ & $-0,062$ & $\mathbf{0 , 5 3 8}$ & $\mathbf{0 , 7 2 5}$ \\
$\mathbf{S}$ & $\mathbf{0 , 7 3 0}$ & $\mathbf{0 , 5 6 5}$ & $-0,111$ \\
$\mathbf{C r}$ & $\mathbf{0 , 6 2 3}$ & $-0,268$ & 0,375 \\
$\mathbf{K}$ & $\mathbf{0 , 7 7 1}$ & $-0,232$ & 0,043 \\
\hline
\end{tabular}

$\mathrm{Na}$ tabela 3 esta representado os fatores encontrados e suas possíveis fontes identificadas neste trabalho.

Tabela 3: Associação de possíveis fontes com os elementos-traço indicadores de cada tipo de poluição.

\begin{tabular}{rll}
\hline Fator & Elementos-Traço & Fonte identificada \\
\hline 1 & $\mathrm{Ti}, \mathrm{V}, \mathrm{Mn}, \mathrm{Fe}, \mathrm{Ni}, \mathrm{Pb}, \mathrm{P}, \mathrm{S} \mathrm{Cre \textrm {K }}$ & Solo, Veículo \\
2 & $\mathrm{~V}, \mathrm{P}, \mathrm{BC}, \mathrm{S}$ & Veículo \\
3 & $\mathrm{BC}, \mathrm{Ni}$ & Veículo \\
\hline
\end{tabular}

O Fator 1 teve maiores participações dos elementos $\mathrm{Ti}, \mathrm{V}, \mathrm{Mn}, \mathrm{Fe}, \mathrm{Ni}$, $\mathrm{Pb}, \mathrm{P}, \mathrm{S} \mathrm{Cr}$ e K , sendo que esse agrupamento indica que uma possível fonte é a ressuspensão da poeira do solo por conter Ti, Fe, e também emissão veicular 
pelo fato de conter S, Cr e Ni. O estudo de Castanho e Artaxo, (2001) também associou os elementos ( $\mathrm{Ti}$ e $\mathrm{Fe}$ ) a ressuspensão de solo.

O Fator 2 teve maiores contribuições para $\mathrm{V}, \mathrm{P}, \mathrm{BC}$, e $\mathrm{S}$, podendo estar associado a emissão de veículos que utilizam combustível com alto teor de enxôfre e vanádio, possívelmente veículos do ciclo diesel. O BC e o S tambem foram associados à emissões veiculares em trabalho anteriores (Oliveira, 2007; Andrade et al., 2010). No trabalho de Castanho e Artaxo, (2001) o Vanádio também foi associado à queima de combustível.

O fator 3 também pode estar associado à emissões veiculares por ter os maiors valores para $\mathrm{BC}$ e $\mathrm{Ni}$. A presença de $\mathrm{S}$ e $\mathrm{V}$ no Fator 2 e de $\mathrm{BC}$ no fator 3 dificultam distinguir claramente o tipo de veículo responsável pelas emissões.

Os 3 fatores identificados podem ser característico de emissões por tráfego, indicando serem as fontes móveis o principal agente responsável pela poluição por partículas finas nos quatro pontos avaliados.

A figura 18 representa a contribuição dos três fatores para os quatro locais amostrados, nota-se que não há diferença significativa na contribuição dos fatores entre as regiões. 


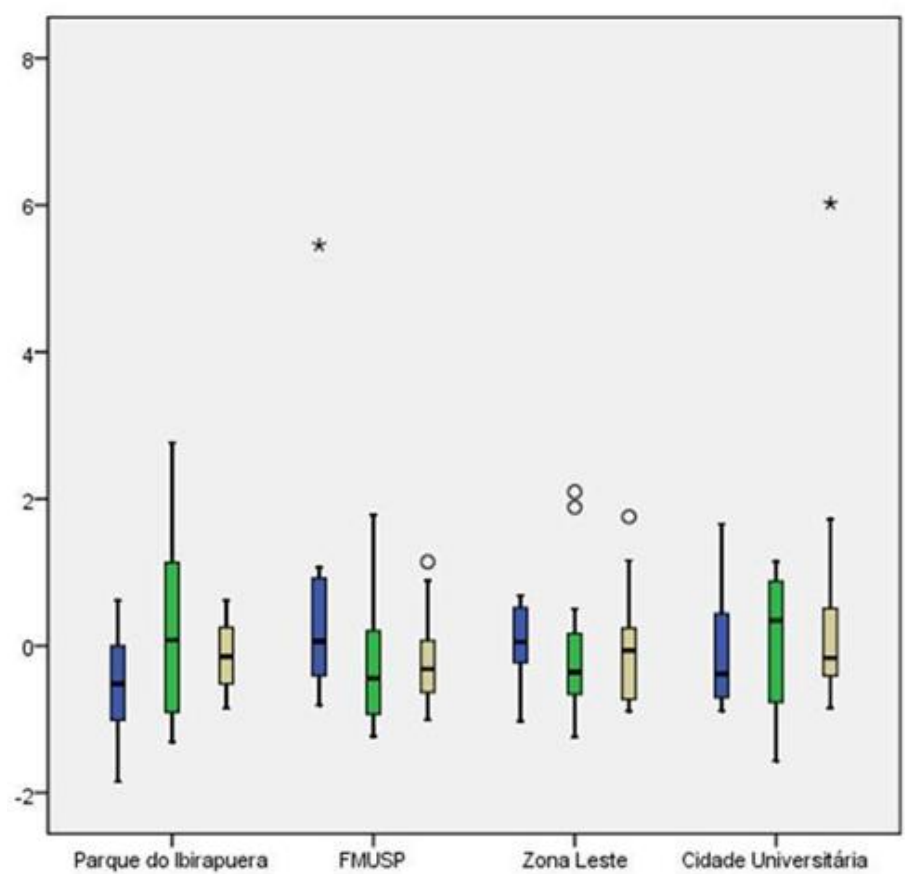

Figura 18: contribuição dos fatores 1,2 e 3 para as regiões amostrada.

O fator 1, que pode estar relacionado ao solo mostrou tendência a ter maior participação na região da FMUSP, neste local o ponto de coleta ficou a poucos metros (aproximadamente 2 metros) da via de tráfego e em local sem pavimento, então, provavelmente a movimentação dos carros e do solo ao redor do amostrador causou a ressuspensão.

O Fator 2, que pode estar relacionado com emissões de veículos pesados, mesmo não apresentando diferença significativa, tende a ser maior na região do Parque do Ibirapuera e na Cidade Universitária. Essas regiões são áreas pouco edificadas e com vegetação.

Apesar da vegetação desempenhar a função de filtragem da poluição atmosférica (Barbosa et al., 2003; Romero, 2001; Martins, 2009) a contribuição do fator 2, que está relacionado a emissões de veículos pesados encontrada neste trabalho foi maior nestes locais, corroborando com os resultados de estudo realizado por Martins (2009) onde é enfatizado que não 
somente a presença de vegetação é responsável pela redução da concentração de PM mas, a quantidade (porcentagem de vegetação) local também influencia nessa redução.

Essa concentração elevada pode estar relacionada também porque o Parque do Ibirapuera é influenciado pelo Corredor Norte-Sul e Avenida dos Bandeirantes, enquanto a Cidade Universitária é circundada de um lado pela Marginal do Rio Pinheiros e em suas outras franjas pela Regis Bittencourt e Raposo Tavares, vias com grande fluxo de veículos pesados.

O fator 3, que relacionamos a emissões veiculares, não apresenta variações entre as regiões amostradas. Provavelmente pelo fluxo constante e intenso de veículos em todos os locais de coleta. 


\section{Considerações Finais}

Este trabalho caracterizou as fontes emissoras e analisou os componentes da poluição atmosférica em quatro regiões distintas dentro da cidade de São Paulo. Verificou também que essas regiões apresentam apenas tendências distintas de variações nas participações dos componentes entre as áreas amostradas, porém sem diferença significativa.

As análises realizadas utilizando as concentrações de $\mathrm{PM}_{2.5}$ mostraram que as maiores concentrações ocorreram no período de inverno em todos os locais amostrados.

Tanto no Inverno quanto no verão foram encontradas concentrações de $\mathrm{PM}_{2.5}$ acima dos valores recomendados pela OMS e certamente são detrimentais para a saúde da população, normalmente aquela que, em face da lentidão do trânsito, dispende uma grande fração do seu tempo em meio ao tráfego pesado. Vale a pena ressaltar que o único ponto de monitoramento próximo a uma via de alto tráfego foi o da FMUSP, que se situava a poucos metros da Avenida Dr. Arnaldo. Os demais pontos podem ser considerados como indicativos de concentrações de background e, portanto, podem indicar grosseiramente a exposição basal da população das regiões estudadas.

A análise do Black Carbon, não mostrou diferença significativa entre as diferentes estações do ano. Porém as concentrações se diferenciaram entre as regiões amostradas, sendo que as maiores concentrações encontradas foram nas regiões do Parque do Ibirapuera e Zona Leste. 
Mostrando que é uma situação preocupante, uma vez que, o Parque Ibirapuera é utilizado diariamente por centenas de pessoas para lazer e prática de exercícios físicos e a zona leste caracterizada como área residencial, deixando uma grande quantidade de pessoas expostas a concentrações de BC que segundo estudos científicos podem causar danos à saúde.

Enfatizando que os esforços para a diminuição das emissões de poluentes e avaliações dos danos causados à saúde das pessoas que habitam e transitam por estes locais, bem como para o meio ambiente, são de extrema importância e devem ser intensificados.

Os resultados deste trabalho são importantes por fornecerem uma estimativa das fontes geradoras de material particulado fino e por aumentar as informações sobre o aerossol atmosférico na cidade de São Paulo. 


\section{Bibliografia}

Albuquerque TTA. Distribuição de tamanho, composição química e identificação das fontes do aerossol atmosférico de São Paulo: um estudo de caso para o inverno de 2003. Dissertação de Mestrado. Instituto de Astronomia, Geofísica e Ciências Atmosféricas - Universidade de São Paulo, 2005.

Baird CA. Química e a poluição do ar na troposfera. In Quimica Ambiental, Porto Alegre: Bookman, 2º Edição 2002; Cap. 3; 107-191.

Barbosa, Ricardo VR, Barbirato, Gianna M, Vecchia, Francisco AS. Vegetação Urbana: Análise experimental em cidade de clima quente e úmido ENCADI-COTEDI-2003.

Braga ALF, Zanobetti. A, Schwartz J. Do respiratory epidemics confound the association between air pollution and daily daths? Eur. Respir. J 2000; 16:723-8.

Braga ALF, Saldiva PHN, Pereira LAA, Menezes JJC, Conceição GMS, Lin CA, et al. Health effects of air pollution exposure on children and adolescents in São Paulo, Brazil. Pediatric Pulmonology 2001; 31:106-13.

Brasseur GP, Orlando JJ, Tyndall GS. Atmospheric Chemistry and Global Change, Oxford University Press, Nova York, 1999.

Brunekreef B, Holgate, ST. Air pollution and health. Lancet 2002; 360(9341):1233 42.

Carlton GN, Smith LB. Exposures to jet fuel and benzene during aircraft fuel tank repair in the U.S. Air Force. Applied Occupational and Environmental Hygiene 2000; v.15(6): 485-491.

Castanho ADA. A determinação quantitativa de fontes de material particulado na atmosfera da cidade de São Paulo. Dissertação de Mestrado, IFUSP. 1999.

Castanho A, Artaxo P. Wintertime and summertime São Paulo aerosol source apportionment study, Atmospheric Environment 2001; 35, 4889 - 4902.

Cataldi M, Maegalho M, Veloso M, Pimentel L. Estudo do transporte de poluentes na região da camada de superfície sob diversas condições de estabilidade atmosférica, XI Congresso Brasileiro de Meteorologia 2000; vol., PP. 2890-2899. 
Conceição GM, Miraglia SG, Kishi HS, Saldiva PHN, Singer JM. Air pollution and child mortality: a time-series study in São Paulo, Brazil. Environ Health Perspective 2001; 109(3 Suppl):347-50.

CETESB. COMPANHIA AMBIENTAL DO ESTADO DE SÃO PAULO, Relatório de qualidade do ar no estado de São Paulo,2006.

CETESB. COMPANHIA AMBIENTAL DO ESTADO DE SÃO PAULO, Relatório de qualidade do ar no estado de São Paulo,2008.

CETESB. COMPANHIA AMBIENTAL DO ESTADO DE SÃO PAULO, Relatório de qualidade do ar no estado de São Paulo,2009.

CETESB. COMPANHIA AMBIENTAL DO ESTADO DE SÃO PAULO. Relatório de qualidade do ar no Estado de São Paulo, 2011.

Dominici F, Peng RD, Bell ML, Pham L, McDermott A, Zeger SL, et al. Fine particulate air pollution and hospital admission for cardiovascular and respiratory diseases. JAMA 2006; 8:1127-34.

Empresa Brasileira de Infraestrutura Aeroportuária. (http://www.infraero.gov.br)

Estação Meteorológica do Instituto de Astronomia e Geofisica e ciências atmosféricas(IAG/USP). (http://www.estacao.iag.usp.br)

Farhat SCL, Paulo RLP, Shimoda TM, Conceição GMS, Lin CA, Braga ALF, et al. Effect of air pollution on paediatric respiratory emergency room visits and hospital admissions. Braz J Med Biol Res 2005; 38:227-35.

Firket J. Sur lês causes dês accidents survenus dans La vallée de La Meuse, lors dês brouillards de décembre 1930. Bull. Acad. Roy. Med. Belg 1931; v. 11, p. $683-741$.

Freitas C, Bremner SA, Gouveia N, Pereira LA, Saldiva PH. Internações e óbitos e sua relação com a poluição atmosférica em São Paulo, 1993 a 1997. Rev Saúde Pública 2004; 38:751-7.

Hobbs PV. Introduction to Atmospheric Chemistry, Cambridge University, Cambridge, 2000.

IAEA - Radioisotope X-Ray Fluorescence Spectrometry. IAEA, Tech 1970; Reports Series n. 115, 102.

INMET - Instituto Nacional de Meteorologia - http://www.inmet.gov.br

Jacobi P. Cidade e Meio Ambiente. São Paulo. Editora Annablume. 1999.

Jacobi P. Do Centro à Periferia - Meio Ambiente e Cotidiano na Cidade de São Paulo. Ambiente \& Sociedade 2000; Ano III - No 6/7. 
Jacobson MZ. Fundamentals of Atmospheric Modeling, 2 ed, Cambridge University Press, Cambridge, 2005.

Kinsey JS, Hays MD.Chemical Characterization of the Fine Particle Emissions from Commercial Aircraft Engines during the Aircraft Particle Emissions experiment (APEX) 1 to 3. Environmental Science Technology 2011; 45:3415-3421.

Kobayashi A, Kikukawa A. Increased formaldehyde jet engine exhaust with changes to JP-8, lower temperature, and lower humidity irritates eyes and respiratory tract. Aviation Space Environ Med 2000; 71: 396-399.

Lacasana M, Esplugues A, Ballester F. Exposure to ambient air pollution and prenatal and early childhood health effects. Eur J Epidemiol 2005; 20:18399.

Lanki T, Pekkanen J, Aalto P, Elosua R, Berglind N, D'Ippoliti D, Kulmala M, Nyberg F, Peters A, Picciotto S, Salomaa V, Sunyer J, Tiittanen P, von Klot S, Forastiere F. Associations of traffic related air pollutants with hospitalization for first acute myocardial infarction: The HEAPSS study. Occup. Environment Med. 2006; 63(12):844-851.

Lin CA, Martins MA, Farhat SCL, Pope III CA, Conceição GMS, Anastácio MVM, et al. Air pollution and respiratory illness of children in São Paulo, Brazil. Paed Peri Epidemiol 1999; 13:475-88.

Lombardo MA. Ilha de calor nas metrópoles. O exemplo de São Paulo. São Paulo, HUCITEC 1985; 244p.

Martins LC, Latorre MRDO, Saldiva PHN, Braga ALF. Air pollution and emergency room visits due to chronic lower respiratory diseases in the elderly: an ecological time-series study in Sao Paulo, Brazil. J Occup Environ Med 2002; 44:622-7.

Martins $\mathrm{MCH}$. Avaliação da interação entre poluição atmosférica e variáveis socio-economicas como agravantes das condições de saúde no município de São Paulo: um estudo de ecologia urbana. Tese (Doutorado em Ciência Ambiental) - Universidade de São Paulo. 2003.

Martins LD, Andrade MF, Freitas ED, Pretto A, Gatti LV, Albuquerque EL, Tomaz E, Guardani ML, Martins MHRB, Junior OMA. Emission factors for gas-powered vehicles traveling through road tunnels in São Paulo, Brazil. Environ. Sci. Technol. 2006; 40(21):6722-6729. doi:10.1021/es052441u.

Martins APG. Casca das árvores filtra a poluição. O Estado de São Paulo, São Paulo, set. 2009; p. C3 - C3, 21.

McClellan R, Jessiman B. Health Context for Management of Particulate Matter, 2009. http://www.narsto.org/section.src?SID=6. 
Medina-Ramón M, Zanobetti A, Schwartz J. The effect of ozone and PM10 on hospital admissions for pneumonia and chronic obstructive pulmonary disease: a national multicity study. Am J Epidemiol 2006; 15:579-88.

Miranda RM, Andrade MF, Worobiec A, Grieken RV. Characterization of aerosol particles in São Paulo Metropolitan Area, Atmospheric Environment,2001;36, 345 - 352.

Miranda RM, Andrade MF, Worobiec A, Grieken RV. Characterisation of aerosol particles in the São Paulo Metropolitan Area. Atmospheric Environment 2002; 36:345-352.

Miranda RM, Andrade MF. Physicochemical characteristics of atmospheric aerosol during winter in the São Paulo Metropolitan Area in Brazil. Atmospheric Environment 2004; 39(33):6188-6193.

Miranda RM, Andrade MF, Fornaro A, Astolfo R, Andre PA, Saldiva PHN. Urban air pollution: a representative survey of PM2.5 mass concentrations in six Brazilian cities. Air Qual. Atmos. Health 2010; DOI 10.1007/s11869010-0124-1.

Miyamoto Y. Eye and respiratory irritants in jet engine exhaust. Aviation Space Environ Med 1986; 57: 1104-1108.

Neas LM, Schwartz J, Dockery D. A case-crossover analysis of air pollution and mortality in Philadelphia. Environ Health Perspect 1999; 107:629-31.

Nucci JC. Análise sistêmica do ambiente urbano, adensamento e qualidade ambiental. Artigo publicado na revista PUC SP Ciências Biológicas e do Ambiente, São Paulo, 1999; v. 1, n. 1, p. 73-88.

Oliveira MGL. Evolução das distribuições de tamanho em massa e número do aerossol atmosférico em São Paulo. Dissertação de Mestrado. Instituto de Astronomia, Geofísica e Ciências Atmosféricas - Universidade de São Paulo, 2007.

Ostro B, Broadwin R, Green S, Feng WY, Lipsett M. Fine particulate air pollution and mortality in nine California counties: results from CALFINE. Environment Health Perspect 2006; 114:29-33. [ATSDR] - Agency for Toxic Substances and Disease Registry. Appendix A: Background Information for jet fuels. 200; 25p.

Pope CA, Dockery DW. Health effects of fine particulate air pollution: lines that connect. J Air Waste Manage Assoc 2006; 50:1308-1320.

Raes F, Dingenen RV, Vignati E, Wilson J, Putaud JP, Seinfeld JH, Peter A. Formation and cycling of aerosol in the global troposphere, Atmospheric Environment 2000;34, $4215-4240$.

Richardson DHS. Pollution Monitoring with Lichens. Richmond Publishing, Slough. 1992. 
Richardson DHS, Shoreb M, Hartreeb R, Richardson RM. The use of X-ray fluorescence spectrometry for the analysis of plants, especially lichens, employed in biological monitoring. The Science of the Total Environment 1995; 97-105.

Ritchie GD, Still KR, Rossi III J, Bekkedal, MY-V, Bobb AJ, Arfsten DP. Biological and Health Effects of Exposure to Kerosenebased Jet Fuels and Performance Additives. J Toxicol Environ Health, 2003; 6(4): 357-451.

Ritchie, I. Risk factors of jet fuel combustion products. Toxicology Letters 2004; 149: 295-300.

Romero MAB. Arquitetura bioclimática do espaço público. Brasília: Editora Universidade de Brasília, 2001, 226p.: il.

Saldiva PH, Lichtenfels AJ, Paiva PS, Barone IA, Martins MA, Massad E, Pereira JC, Xavier VP, Singer JM, Bohm GM. Association between air pollution and mortality due to respiratory diseases in children in São Paulo, Brazil: a preliminary report. Environ Res 1994; 65(2):218-225.

Saldiva PHN, Braga ALF, Pereira LAA. Health effects of ambient levels of airpollution. In: Hogan DJ, Berquó E, Costa HSM, editors. Population and environment in Brazil: Rio +10 . Campinas: Comissão Nacional de População e Desenvolvimento/Associação Brasileira de Estudos Populacionais/Núcleo de Estudos de População, Unviersidade Estadual de Campinas; 2002. p. 207-23.

Sánchez-Ccoyllo OR, Ynoue RY, Martins LD, Astolfo R, Miranda RM, Freitas ED, Borges AS, Fornaro A, Freitas H, Moreira A, Andrade MF Vehicular particulate matter emissions in road tunnels in São Paulo, Brazil. Envrionmental Monit. Assess. 2008;149(1-4):241-249. doi: 10.1007/ s 10661-008-0198-5.

Schwartz J. Air pollution and hospital admissions for heart disease in eight U.S. Countries. Epidemiology 1999; 10:17-22.

Secretaria dos Transportes Metropolitanos do governo do estado de São Paulo (http://www.stm.sp.gov.br)

Seinfeld $\mathrm{JH}$, Pandis SN. Atmospheric chemistry and physics: from air pollution to climate change, willey, new york, 1998.

Stolzel M, Breitner S, Cyrys J, Pitz M, Wölke G, Kreyling W,Heinrich J, Wichmann HE, Peters A. Daily mortality and particulate matter in different size classes in Erfurt, Germany. J. Expo Science Environment Epidemiology 2007; 17(5):458-467.

Tunnicliffe WS, O`Hickey SP, Fletcher TJ, Miles JF, Burge PS, Ayres JG. Pulmonary function and respiratory symptoms in a population of airport workers. Occupational Environmental Medicine, 56: 118-123, 1999. 
Turner W, Spengler JD. Low Flow Rate Sharp Cut Impactors for Indoor Air Sampling: Design and Calibration. JAPCA 1987; 37:1303-1307.Volume 37, No.11.

Veleda DRA. Ajuste do Campo do Vento Sobre Topografia Complexa Aplicado a um Modelo de Dispersão de Poluentes. Dissertação de Mestrado, IAG, Universidade de São Paulo, São Paulo.79 p. 2001.

Wark K, Warner CF, Davis WT. Air pollution its origin and control. 3.ed. Menlo Park, Califórnia, Addison-Wesley. 1998.

Watson JG, ZHU T, CHOW JC, Engelbrecht J, Fujita EM, Wilson WE. Receptor modeling application framework for particle source apportionment. Chemosphere 2002; 49, 1093-1136.

WHO - World Health Organization. Air quality guidelines for particulate matter, ozone, nitrogen dioxide and sulfur dioxide - Global update 2005.

Yamasoe MA. Estudo da composição elementar e iônica de aerossois emitidos em queimadas na Amazônia. Tese de Mestrado, Instituto de Física, Universidade de São Paulo. 1994. 
